UNIVERSITÉ DU QUÉBEC

\author{
MÉMOIRE PRÉSENTÉ À \\ L'UNIVERSITÉ DU QUÉBEC À CHICOUTIMI
}

COMME EXIGENCE PARTIELLE

DE LA MAITTRISE EN ART (M.A.)

PAR

JOSÉE LAPORTE

LA MISE EN ESPACE AU THÉÂTRE :

UNE PRATIQUE INTERDISCIPLINAIRE ET HÉTÉROMORPHIQUE

AVRIL 2011 


\section{RÉSUMÉ}

Cette recherche création se présente comme un parcours qui se construit par l'action de diverses conjonctions rhizomatiques. Une trajectoire qui permet de relever plusieurs notions et procédés issus des avant-gardes historiques afin de définir une pratique théâtrale interdisciplinaire et performative.

Elle repose sur une articulation théorique qui admet le concept de mise en espace comme une pratique à part entière. Elle s'attache à montrer comment l'espace est un opérateur intermédial de rencontres interdisciplinaires et hétéromorphiques qui dynamise la rencontre avec l'Autre. Elle renouvèle les paramètres et les codes du théâtre traditionnel dans une dynamique de la complexité.

La création théâtrale contemporaine se déploie dans un théâtre du dispositif qui autorise des couplages intermédiumniques inédits. L'hétérogénéité et la déhiérarchisation des signes engagent alors le spectateur dans un rapport dialogique hétéromorphe. Le théâtre performatif se caractérise aussi par une attention portée aux processus de création ainsi qu'aux dimensions expérientielle, interrelationnelle et événementielle.

L'approche phénoménologique catalyse autant la réflexion sur l'altérité, l'être au monde, la coprésence et l'être-ensemble contemporain, qu'elle motive la mise en place de protocoles pratiques pour diriger les acteurs et les non-acteurs et conceptualiser la relation avec le spectateur. Elle place la parole, la corporéité, la sensation, la matérialité et l'espace parmi les structures à la base de ce travail de recherche et d'expérimentation pour engager un dialogue qui questionne et ravive notre rapport au monde, aux autres et à soi.

Le mouvement entre la théorie et la pratique est au cœur de cette démarche de création. Elles s'interpénètrent et se nourrissent l'une de l'autre dans une dynamique dialectique. C'est pour faire ressentir l'ensemble de ce processus de création qu'il m'est apparu pertinent de proposer un parcours déambulatoire comme une allégorie stimulante pour répondre des notions et des procédés avancés dans ce mémoire.

événement - mise en espace - interdisciplinarité - intermédialité - théâtre performatif déhiérarchisation - hétérogénéité - langages - dynamique de la complexité - processus de création - espace - temps - dispositif - hétérotopie - corporéité - parole - sensation aisthesis - altérité- spectateur - participation - coprésence - être-ensemble - communauté - phénoménologie - dialogisme - hétéromorphique - théâtre contemporain - happening déambulatoire - rhizome - in situ - installation - art contextuel - théâtre de recherche et d'expérimentation - œuvre ouverte 


\section{REMERCIEMENTS}

Je veux d'abord chaleureusement remercier mon directeur de recherche, monsieur JeanPaul Quéinnec.

De même, je souhaite manifester toute ma reconnaissance et mon estime aux membres de mon jury, messieurs Denys Tremblay et Hervé Bouchard.

Je tiens aussi à remercier ma famille pour leur soutien inestimable durant toute cette aventure de recherche et de création.

De plus, il me semble important de souligner la remarquable collaboration de 1'UQAC, et plus particulièrement celles de madame Lyne Girard et de monsieur Jérôme Gravel, sans qui ce projet de création n'aurait pu s'actualiser dans sa forme déambulatoire.

Je veux également remercier le CELAT pour la bourse d'excellence de deuxième cycle qu'ils m'ont accordée pour terminer cette recherche création.

Je souhaite saluer le travail de Dominick Parenteau-Lebeuf et la remercier pour m'avoir généreusement cédé ses droits.

Enfin, je veux témoigner de ma plus grande considération à tous les précieux collaborateurs qui se sont engagés dans ce processus de création.

À tous ceux et celles dont la présence m'accompagne. 


\section{LISTE DES FIGURES}

1. Jérémie des mains bleues à la frontière du réel................................50

2. Vue partiale et latérale de l'espace des mains bleues............................51

3. Les acteurs en situation de jeu dans l'espace des mains bleues..................52

4. Espace vide pour l'icône 1: Vive la Canadienne ...............................................64

5. Espace vide pour l'icône 2 : Vices cachés...................................66

6. Espace vide pour l'icône 3 : Nacre C.......................................69

7. Dispositif boûte-bunker de l'icône 4: Catwalk, sept voix pour sept voiles...........71

8. Plan mitoyen du dispositif de l'icône 4 : Catwalk, sept voix pour sept voiles......73 
TABLE DES MATIÉRES

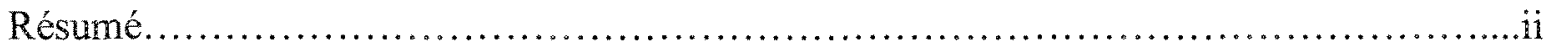

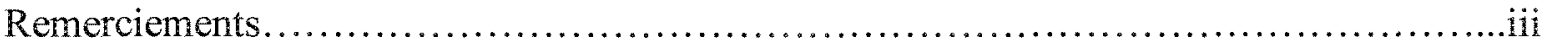

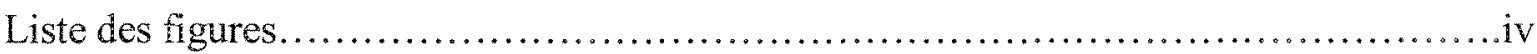

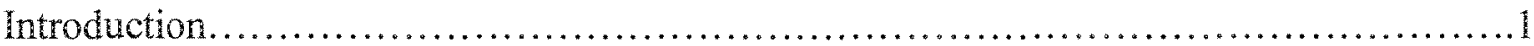

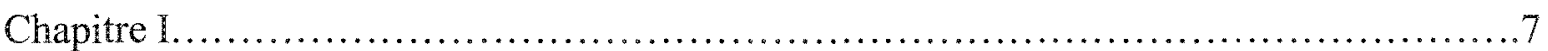

Filiations esthétiques

De quelques avant-gardes historiques vers la définition d'un théâtre interdisciplinaire et performatif

Chapitre II

L'espace au théâtre : un opérateur intermédial de rencontres hétéromorphiques Du déploiement interdisciplinaire qui dynamise la rencontre avec l'Autre

Chapitre III

La mise en espace : une pratique interdisciplinaire et hétéromorphique

Chapitre IV

La création de Filles de guerres lasses de Dominick Parenteau-Lebeuf Un parcours déambulatoire

Conclusion.

Bibliographie. 
INTRODUCTION 
Le monde est ma provocation'.

[...] le théâtre me permet de n'appartenir à aucun lieu, de n'être pas ancré à une unique perspective, de rester en transition ${ }^{2}[\ldots]$

Ma démarche artistique est une libre circulation interdisciplinaire qui veut prêter attention à la provocation du monde en adoptant une posture critique et ludique par rapport aux enjeux de notre temps. Mon projet esthétique (et politique) ne consiste pas à esthétiser le réel, mais à m'exposer à l'altérité - interne et externe - pour l'approfondir et la remodeler de manière à produire des choses sensibles « imprégnées de savoir et d'imagination ${ }^{3}$ ». Je veux témoigner du monde qui m'entoure et engager un dialogue qui questionne et ravive notre rapport au monde, aux autres et à soi. En ce sens, ce projet appartient au champ phénoménologique et à l'aisthesis « une théorie de la sensibilité et des sensibles où la beauté est moins un jugement de valeur qu'une faculté de recréer du sens et de l'existence, de susciter ces nouvelles formes de « subjectivation » que voulait Foucault, pour construire une "herméneutique du sujet » ouverte au souci de soi et de l'autre"».

\footnotetext{
'Gaston Bachelard, L'Eau et les Rêves, Paris, José Corti, 1942, p. 181.

${ }^{2}$ Eugenio Barba, Le canoe de papier. Traité d'anthropologie théatrale, Saussan, L'Entretemps, coll. «Les voies de l'acteur », 2004, p. 25.

${ }^{3}$ Expression tirée du livre de Baldine Saint Girons, L'acte esthétique, Paris, Klincksieck, coll. « 50 questions "2008, p. 15 .

${ }^{4}$ Christine Buci-Glucksmann, Esthétique de l'éphémère, Paris, Gallée, 2003, p. 20.
} 
Considérant que le théâtre est encore, par lui-même, un lieu communautaire, associé à une idée de collectivité vivante, j'ai voulu investir cette pratique parce qu'elle me permet de mettre en jeu un certain nombre d'utopies. Et puis, bien que ce ne soit pas "à la mode" de dire tout haut que l'on se sent en mouvement vers des utopies ${ }^{5}, j$ 'ai tout de même envie d'affirmer quelques unes de mes projections. À ce titre, j'estime que le thêâtre est un formidable médium pour éprouver une pensée qui s'actualise à la fois dans un mouvement théorique et pratique. Le théâtre m'ancre dans une expérience sensible du monde et admet des transfusions, des disséminations et une intercommunication qui alimentent et stimulent mes élans de créations.

Mon travail de recherche création en théâtre se développe donc dans une perspective de recherche et d'expérimentations interdisciplinaires qui pense la rencontre avec l'Autre dans le dessein de questionner l'espace, le temps, la corporéité, la parole, la sensation d'être au monde, la coprésence et l'être-ensemble contemporain. C'est par l'expérimentation de différents dispositifs contextuels que je souhaite «engager une idée de la communauté comme présence à soi, opposée à la distance de la représentation ${ }^{6}$ ". Une collectivité hétérogène, une communauté éphémère vivante et en mouvement opposée à des spectateurs soumis aux mythes spectaculaires ef à l'illusion de la mimesis. Une manière de produire des utopies localisées ${ }^{7}$ où le langage comme noyau de la culture et de

\footnotetext{
${ }^{5}$ On vit dans époque opaque comme le dit si bien le chanteur-poète Richard Desjardins.

${ }^{6} J a c q u e s$ Rancière, Le spectateur émancipé, Paris, La Fabrique, 2008, p. 11-12.

${ }^{7}$ En référence à la notion d'hétérotopie développée par Michel Foucault que je décrirai dans le second chapitre de ce mémoire.
} 
la sensation peut se manifester en s'adressant « non seulement à l'esprit mais aux sens, et par les sens, à atteindre des régions plus riches et fëcondes de la sensibilité en mouvement ${ }^{8}$ ».

Dans cet essai, je développerai le concept de mise en espace et montrerai qu'il est bien plus qu'une locution; il constitue un formidable détonateur de liberté conceptuelle pour mettre en place des dispositifs qui proposent des expériences inédites du corps, de l'espace et du temps. Ainsi, en développant ce concept artistique de mise en espace dans une dynamique interdisciplinaire et performative, je peux envisager la production théâtrale comme une manière d'enchâsser plusieurs formes d'expression différentes (écriture hétéromorphique) sur le plateau de théâtre (ou dans tout autre espace). De sorte qu'en considérant l'espace comme un opérateur intermédial de rencontres (entre les acteurs et les spectateurs, mais aussi entre les disciplines), je peux concevoir la création théâtrale comme une production événementielle qui occasionne une expérience à la fois résolument personnelle et plurielle.

Dans le premier chapitre, $\mathrm{j}$ 'exposerai succinctement un ensemble de filiations esthétiques issues des avant-gardes historiques. Cette traversée me permettra de décrire en quoi certains de ces mouvements exercent de l'influence sur ma pratique artistique mais

\footnotetext{
${ }^{8}$ Antonin Artaud, «Le Théatre et son double » in CEuvres, Paris, Gallimard, coll. « Quarto », 2004, p. 578. Son ouvre protéiforme constîue une source d'inspiration majeure dans mon travail de recherche et d'expérimentations.
} 
aussi, m'amènera à me situer dans le flux mouvant et hétérogène du théâtre contemporain. Ces repérages sont autant de notions et de procédés qui me seront utiles pour développer ma conception de l'interdisciplinarité et pour définir le théâtre performatif.

Dans le second chapitre, je formulerai ma problématique sur le plan d'une dramaturgie de l'espace au théâtre et présenterai l'articulation théorique qui soutient ma démarche de conceptualisation. Cette approche me permet d'envisager l'intermédialité de l'espace au théâtre et potentialise des déploiements interdisciplinaires, hétéromorphiques et interrelationnels inédits. Je développerai les concepts-clé qui permettent de comprendre en quoi ces perspectives renouvellent et transforment la pratique théâtrale contemporaine, notamment en ce qui concerne les interactions avec le spectateur.

Le troisième chapitre constitue un développement pratique de ma démarche conceptuelle. Il veut consacrer le concept de mise en espace comme pratique théâtrale interdisciplinaire et hétéromorphique pour rencontrer l'Autre. Je montrerai comment l'interdisciplinarité est une ouverture à l'altérité artistique et à l'accroissement de pratiques collaboratives inédites. Je présenterai aussi ma méthode d'inspiration phénoménologique qui m'engage dans un certain nombre de protocoles pratiques avec les acteurs, ainsi qu'à l'endroit des spectateurs, pour composer les différentes stratégies d'énonciation qui soutiendront ma proposition de création. 
En dernier lieu, dans le quatrième chapitre, je décrirai l'événement Filles de guerres lasses de Dominick Parenteau-Lebeuf. Cette création se présente sous la forme d'un parcours déambulatoire qui se déploiera en quatre lieux différents sur le territoire de 1'UQAC. Le choix de proposer une déambulation s'est imposé afin de mettre en évidence les potentialités de l'espace comme opérateur de rencontres hétéromorphiques mais aussi, pour faire ressentir la nature expérientielle et processuelle de la création théâtrale contemporaine. En outre, je souhaite inviter le spectateur dans un processus interrelationnel et événementiel où il pourra expérimenter l'en-cours d'une démarche et s'y sentir interpellé de différentes façons. J'espère ainsi soumettre de nouvelles configurations de l'espace et du temps afin qu'ils soient vécus comme des successions d'événements inouïs, hétérogènes et éphémères, (par opposition au temps linéaire des grands récits totalisants), dans le but de déplacer le spectateur des positions (rôle, place) traditionnellement attendues au théâtre. On peut dire enfin que cette recherche création est traversée par le désir de penser autrement le rapport au public, accompagnée d'une remise en cause du lieu théâtre comme institution. Elle relève les potentialités d'une pratique performative qui puisse se déployer comme un processus de création qui révèle l'importance de l'espace et de la spatialité de l'existence comme être au monde. 


\section{CHAPITRE}

\section{FLLTIONS ESTHETIOUES}

DE QUELQUES AVANT-GARDES HISTORIQUES VERS LA DÉFINITION DUN THEÂTRE INTERDISCIPLINAIRE PERFORMATIF 
Protestation contre l'idée séparée que l'on se fait de la culture, comme s'il y avait la culture d'un côté et la vie de l'autre; et comme si la vraie culture n'était pas un moyen raffiné de comprendre et d'"exercer" la vie".

S'approprier définitivement le réel à des fins subversives ${ }^{l 0}$.

Pour comprendre les visées esthétiques et politiques qui m'animent, il me semble nécessaire de faire une rapide traversée historique afin de saisir le mouvement, le flux qui impulse ma démarche de création, mais aussi pour me situer dans un courant, en tension vers une pratique interdisciplinaire et performative au théâtre. Considérant que « les hybridations ne dénient pas les identités, elles y renvoient en les relativisant "', j'estime que les langages développés depuis les avant-gardes historiques constituent un arsenal de stratégies expressives servant à opérer des mutations de première importance pour le théâtre contemporain.

Le monde des arts, à partir du début du XXe siècle, est devenu hétérogène, multiple et pluriel. Il n'est plus un espace homogène [...] Ses potentiels créatifs éclatent, débordent les catégories artistiques et esthétiques et se brisent en une multitude de pratiques, d'idées et de concepts ${ }^{12}$.

Les relations que le théâtre développe avec les mouvements des avant-gardes sont manifestes. Dans cette perspective, j'exposerai quelques-uns de ces courants de l'art qui ont contaminé le théâtre afin d'y retrouver les composantes qui sont caractéristiques de

\footnotetext{
"Antonin Artaud, Euvres, «Le Théâtre et son double », Paris, Gallimard, coll. « Quarto », 2004, p. 507.

${ }^{10}$ Dick Higgins, cit. d'après Olivier Lussac, Happening \& Fluxus polyexpressivité et pratique concrète des arts, Paris, L'Harmattan, coll. « Arts \& Sciences de l'art 》, 2004, p. 17.

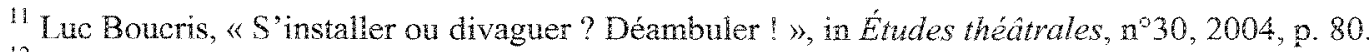

${ }^{12}$ Olivier Lussac, op.cit. p. 18
} 
l'esthétique théâtrale contemporaine (notamment le déplacement de l'œuvre à l'événement, la multidisciplinarité, la volonté de rendre le spectateur actif, l'esprit ludique et critique, etc.). Ce continuum historique ne sert qu'à relever des éléments qui exercent de l'influence sur ma pratique dramaturgique. Il commence par Dada, passe par les futuristes, migre vers Fluxus, pour ensuite rendre hommage à Guy Debord et aux situationnistes, et tente enfin de décrire de manière très concise, le happening et la performance. Cette trajectoire me permettra ensuite d'établir des liens avec ma conception de l'interdisciplinarité et du théâtre performatif, en somme une grande constellation. Précisons toutefois que je ne présente pas une recherche théorique, mais une délimitation théorique, esthétique, voire idéologique au regard de ma pratique. Ceci implique un développement de références théoriques très mesuré qui doit se lire comme un repérage partiel, voire partial d'une histoire de la scène. Si cette filiation paraît s'écarter d'une appartenance attendue du champ théâtral, elle pourrait correspondre davantage à celle sur laquelle repose un certain théâtre contemporain.

Inspirée par Dada pour mener des explorations interdisciplinaires, je souhaite m'inscrire dans cette constellation d'individus libres et ouverts qui ont su accueillir l'Autre ${ }^{13}$ pour construire leur identité. Mouvement fondé en 1916 à Zurich par Tristan Tzara, des artistes de toute l'Europe se sont approprié Dada dans le but de « rappeler qu'il

\footnotetext{
${ }^{13}$ En l'occurrence chez Dada dans les années 1916-1920, on interrogeait la place et les conditions des femmes dans la société. Ils ont été les premiers dans l'histoire de l'art à accueillir les femmes comme partenaires à part entière, non seulement comme des muses ou des modèles.
} 
y a au-delà de la guerre et des patries des hommes indépendants qui vivent d'autres idéaux $^{14} \%$. Il n'y a pas un style dada: son unité réside tout au plus dans une commune recherche pluridisciplinaire et le jeu avec les convenances et les conventions, aussi bien artistiques que sociales et politiques. Ce mouvement valorisait ainsi un esprit ludique et critique et rejetait la raison et la logique. Le ready-made de Duchamp ${ }^{15}$, par exemple, inaugurait la permutation de l'œuvre en événement, valorisant le processus plutôt que le produit, déclenchant ainsi une remise en cause du statut esthétique de l'œuvre (les critères normatifs sur l'art, le beau, le bon goût et sa marchandisation), avec le réel de l'urinoir. En fait, ces artistes "recherchaient la plus grande liberté de créativité, pour laquelle ils utilisèrent tous les matériaux et formes disponibles. Ils recherchaient également cette liberté dans le langage, qu'ils aimaient lyrique et hétéroclite ${ }^{16} »$. De son côté, Kurt Schwitters, fondateur du mouvement Merz, faisait des collages et des assemblages de toutes sortes sur la base d'une équivalence esthétique des matériaux utilisés. Il s'appropriait des fragments, des « rebuts de la société industrielle et urbaine, faisant entrer la réalité quotidienne dans l'art, sans idée de message politique ou d'esthétique d'opposition, mais

\footnotetext{
${ }^{14}$ Hugo Ball (co-fondateur de Dada avec Tristan Tzara), tiré de l'éditorial de l'unique numéro de la revue Cabaret Voltaire. http:// fr.wikipedia.org/wiki/Dadaïsme (consulté le 15/02/2008)

${ }^{15}$ Daniel Vander Gucht, Ant et politique. Pour une redéfinition de l'art engagé, Bruxelles, Éditions Labor, coll. «Quartier Libre », 2004, p. 53. "L'art contemporain depuis Dada, avec le ready-made (choisi mais non réalisé par Duchamp), les happenings, les installations et autres actions, a déplacé le foyer de la pratique de l'œuvre finie vers l'intention créatrice, privilégiant l'art qui ressemble à la vie plutôt que l'art musée (fût-il contemporain), suivant la distinction qu'opère Allan Kaprow entre l'art-like art et le life-like art ».

${ }^{16} \mathrm{http} / /$ fr.wikipedia.org/wiki/Dadaïsme (consulté le 15/02/2008)
} 
avec la volonté à partir de 1920, de fonder un "art total Merz", embrassant l'architecture, le théâtre, la poésie et la musique ${ }^{17} \gg$.

À la même époque, la richesse polyexpressive des expérimentations futuristes, notamment en matière de recherches sonores, conjuguée à l'action combinatoire de divers matériaux et de machines de toutes sortes, va donner naissance à la poésie sonore. Leur pratique concrète de déstructuration de la syntaxe et de la musique, ainsi que leur démarche de poétisation des bruits vont mener au bruitisme et à L'Art des bruits de Luigi Russolo. Le bruit est alors considéré pour ses qualités expressives (et révélatrices) dans une structure sonore ouverte. «Ce sont les notions de parasitage, de brouillage et d'élargissement des catégories qui entrent dans les arts. Russolo a mis en valeur un monde de la dissonance et de la complexité $e^{18} »$ pour rapprocher l'art et la vie. Cette importante mouvance semble avoir irrigué tout le XXe siècle jusqu'aux travaux de Fluxus, de John Cage et de nos contemporains en matière de recherche sonore. Elle permet notamment de considérer que le silence est une perception puisque nous sommes constamment entourés de sons. Cela implique nécessairement de reconnaitre que le monde sonore échappe à toute tentative de contrôle. C'est par l'emploi de divers procédés tels que le détournement, la manipulation, la théâtralisation qu'ils vont alimenter une pratique de création sonore et musicale complètement inédite. Les fondements de leur recherche s'appuient sur l'indétermination ouvrant l'art au jeu de la performance, le processus de création par opposition au résultat, la

\footnotetext{
${ }^{17}$ http:/fr.wikipedia.org/wiki/Kurt_Schwitters (consulté 15/02/2008)

${ }^{8}$ Olivier Lussac, op.cit. p. 39.
} 
spontanéité, l'action directe, l'espace et le work in progress. Toutes ces explorations sont toujours d'importants moteurs de recherche dans la création contemporaine.

Dans son essai, Happening \& Fhuxus polyexpressivité et pratique concrète des arts,

Olivier Lussac décrit la nature du mouvement en ces termes :

Fluxus est dès lors non seulement lié à l'histoire d'un cercle d'artistes, mais est encore considéré comme un libre jeu de l'art et comme un esprit sans conséquences, qui perdurent jusqu'à aujourd'hui, et qui supposent les idées de flux, de mutation et d'interrelation entre les arts. Il implique subséquemment pluralisme, choc des créations et des méthodes. Au-delà d'une réconciliation des médias entre eux, de l'art et de la vie, il signifie l'écoulement ou l'idée de la fluidité non contrariée de l'esprit'.

C'est ainsi que Fluxus, comme beaucoup de mouvements d'avant-garde qui constituent notre fond contemporain, ne peut pas se voir attribuer une formulation figée, invariable ou permanente. Cette esthétique du flux fait plutôt apparaître des filiations esthétiques et des éléments caractéristiques de la diversité des pratiques interdisciplinaires en art contemporain, et plus spécifiquement au théâtre.

Fluxus est donc l'association d'éléments disparates. Il crée de nouveaux moyens pour prendre conscience du monde qui nous entoure, et prépare à une sorte de Lebenkunstwerk ${ }^{20}$, « œuvre d'art de vivre » $[\ldots]$ il cherche à établir des relations nonhiérarchisées [sic] entre les différentes formes d'art. Ces relations sont de nature

\footnotetext{
${ }^{19}$ Olivier Lussac, op.cit. p. 14

${ }^{20}$ En référence au concept esthétique de Gesamtkunstwerk, issu du romantisme allemand et associé à Wagner, désignant « ceuvre d'art totale ».
} 
participative. Fluxus n'est donc pas un style, ni une procédure artistique. C'est plutôt une expérience et un état d'esprit qui se réfèrent à la totalité des activités sociales ${ }^{21}$.

Fluxus s'appuie aussi sur l'iconoclaste Guy Debord et sur les activités insolentes et inventives de l'Internationale situationniste. Ce mouvement, pour qui la théorie et la pratique étaient inséparables, soutenait que le caractère révolutionnaire de l'art et de ses formes expressives ne pouvait se réaliser qu'en dépassant l'art dans une critique de la vie quotidienne, dans le but de transformer les modalités de présence de la société capitaliste. Dans la Théorie des moments et construction des situations" ${ }^{22}$, on peut lire que « $L a$ situation, étroitement articulée dans le lieu, est complètement spatio-temporelle. [...] Les moments construits en "situations " pourraient être considérés comme les moments de rupture, d'accélération, les révolutions dans la vie quotidienne individuelle ». Debord présente la situation construite en ces termes: "Une telle production artistique rompt radicalement avec les ouvres durables. Elle est inséparable de sa consommation immédiate, comme valeur d'usage essentiellement étrangère à une conservation sous forme de marchandise ». Cette manière de concevoir l'énonciation artistique, étrangère à toute possibilité de marchandisation, inspira des mouvements tels que le happening, les événements fluxus et la performance.

\footnotetext{
${ }^{21}$ Olivier Lussac, op.cit. p. 20.

${ }^{22}$ Internationale situationniste, Paris, Librairie Arthème Fayard, 1997, p. 118-119.
} 
Cet essai s'enracine, d'une certaine façon, dans une forme réquisitoire contre la Société dl spectacle ${ }^{23}$. Considérant que la marchandisation de tous les aspects de la vie et la spectacularisation du monde persiste et s'intensifie, il m'apparait vital de faire preuve d'exigence critique pour résister un tant soit peu à l'instrumentalisation de la culture. Pour reprendre les termes de Debord: "Toute la vie des sociétés dans lesquelles règnent les conditions modernes de production s'annonce comme une immense accumulation de "spectacles". Tout ce qui était directement vécu s'est éloigné dans une représentation" ${ }^{24}$ ". Tout le projet des situationnistes, dont Debord fut le principal théoricien et un important protagoniste dans l'aventure de l'Internationale situationniste, qui s'échelonna de 1957 à 1972, consistera précisément à créer des situations qui permettent de renverser ce qui fonde le principe de l'aliénation, à savoir la passivité. «Et sans doute notre temps... préfêre l'image à la chose, la copie à l'original, la représentation à la réalité, l'apparence à l'être... Ce qui est sacré pour lui, ce n'est que l'illusion, mais ce qui est profane, c'est la vérité. $[\ldots]^{25}{ }$. 11 m'apparaît nécessaire de m'opposer à cette transformation programmée d'acteurs sociaux en consommateurs passifs, chosifiés en groupes, définis en amont par les lois du marché et du spectacle généralisé. Je reviendrai d'ailleurs plus longuement sur la place décisive du spectateur dans ma pratique dans le second chapitre de cet essai.

\footnotetext{
23 Je fais ici référence à l'essai critique de Guy Debord, La Société du spectacle qui dénonce l'aliénation qu'engendre la société de consommation. Le concept de spectacle constitue une clé importante pour comprendre le monde d'aujourd'hui (où le spectateur, au profit de l'objet contemplé, se déréalise complètement comme acteur). Cette cuvre me semble fondamentale pour élaborer une pensée critique de l'activité du spectateur-consommateur. Les activités du Lettrisme et de l'nternationale situationniste avec leurs techniques de dépassement par l'art, telles que la dérive, le détournement, l'action directe, sont inspirantes et constituent des sillons invitant à explorer.

${ }^{24}$ Guy Debord, "La séparation achevée », in Internationale situationniste, p. 539.

${ }^{25}$ Feuerbach en préface à La Société du spectacle de Guy Debord in Internationale situationniste, op.cit. p. 539.
} 
En 1960, sous la houlette d'Allan Kaprow, le happening fait son apparition. Ces spectacles, qui ne s'assujettissaient à aucune configuration précise, empruntaient librement à la peinture, à la sculpture, à la musique et au théâtre en s'autorisant toutes les audaces et toutes les dérives. Le happening n'était pas que des actions, mais un ensemble de phénomènes visuels et sonores essentiellement cumulatifs. Sans posséder de territoire spécifique ni de philosophie propre, il comprenait essentiellement quatre conditions: l'indétermination, le hasard, le caractère éphémère et l'usage de matériaux éphémères. Ainsi, en choisissant le mot happening, Kaprow indique bien de quel type d'activité il s'agira: "Non seulement il transmet une signification neutre d" "événement" ou de "fait", mais il suggère également quelque chose d'imprévu, quelque chose de fortuit, qui peut être non intentionnel, non dirige $e^{26} \ggg$.

Un autre aspect déterminant du happening est l'implication des spectateurs. Cela ne signifie pas qu'ils devaient prendre une part active à l'action, mais plutôt que le public était installé dans l'espace, l'empêchant ainsi de se sentir à distance du spectacle. "Il est physiquement au caur de l'action, même s'il n'agit pas lui-même ${ }^{27} \gg$. Néanmoins, les happenings ne préservaient que bien rarement, de bout en bout, le confort matériel et psychologique des spectateurs. Enfin, il me semble incontournable de faire mention de l'inspirante circulation interdisciplinaire de John Cage, qui ne fut pas qu'un catalyseur sur le plan musical, mais l'incarnation d'une forme de pensée et de travail qui est toujours bien

\footnotetext{
${ }^{26}$ Olivier Lussac, op.cit. p. 106.

${ }^{27}$ Ibid., p. 109.
} 
visible aujourd'hui. Tel que Duchamp, lui aussi a su, par ses diverses expérimentations in vivo, faire apparaitre la nature processuelle de l'art qui se veut comme une action dans la vie même: «Vous dites : le réel, le monde tel qu'il est. Mais il n'est pas, il devient! Il bouge, il change !... L'on est plus près de cette réalité en disant... il "se présente" : ce qui signifie qu'il n'est pas là, existant en tant qu'objet. Le monde, le réel n'est pas un objet. C'est un processus ${ }^{28} »$.

Définir la performance et la circonscrire comme pratique artistique est une entreprise plutôt problématique puisque historiquement la performance a servi à décloisonner les genres, transgresser les limites et ouvrir les frontières. Néanmoins, avec Roselee Goldberg, on a pu voir que la performance a joué un rôle de catalyseur dans l'histoire de l'art au XXe siècle. Il semble bien que, chaque fois qu'un mouvement s'est trouvé dans une impasse, les artistes ont adopté la performance pour briser les catégories et rompre avec les normes et conventions en vigueur dans le but d'apporter des réponses novatrices et de réorienter l'action. En ce sens, Goldberg présente la performance comme « celle d'une " avant avant-garde ». Si l'essentiel des textes consacrés de nos jours à l'ouvre des futuristes, des constructivistes, des dadaïstes et des surréalistes continue à se focaliser sur les objets d'art, c'est le plus souvent la performance qui fut l'activité fondatrice de ces mouvements $[\ldots]^{29} \%$ On pourrait alors considérer la performance comme une posture critique par rapport à son temps qui potentialise les mutations et les hybridations pour

\footnotetext{
${ }^{28}$ John Cage cité par Olivier Lussac, op.cit. p. 142.

${ }^{29}$ Roselee Goldberg, La Performance, du futurisme à nos jours, Paris, Thames \& Hudson, 2006, p. 7.
} 
redéfinir de nouveaux espaces aux pratiques existantes. «L'histoire de l'art de la performance au XXe siècle est celle d'une technique permissive, aussi flexible qu'ouverte, aux variables infinies et exécutées par des artistes désireux d'outrepasser les limitations de formes d'art plus établies et résolus à soumettre leur art directement au public ${ }^{30} \ggg$. En raison de sa nature, la performance se défile devant toute tentative de définition. Elle est un art vivant, une mise en pratique critique qui vise à déplacer le spectateur des repères attendus afin qu'il perçoive autrement l'objet-art.

Cette traversée, forcément subjective et parcellaire, me conduit à tenter de définir en quoi consiste pour moi une pratique interdisciplinaire au théâtre. D'abord, le préfixe inter invite à se situer, dans un espace entre, critique et ludique, qui déplace et crée des zones de frottement, qui permettent la mise en relation de différentes pensées et pratiques. C'est par ces mises en relation hétérogènes qu'émerge une pratique singulière. C'est aussi par une transfusion de savoirs et de pratiques qui permettent de dépasser les frontières et les conventions, communément définies entre les arts et les savoirs, entre soi et les autres que je peux expérimenter de nouveaux modes de relation aux signes et à l'altérité. J'estime donc être-entre dans une position intermédiale en relation avec une constellation multidisciplinaire. En ce sens, le théâtre m'offre un espace de jeu intermédial inouï au regard de ses composantes hétérogènes qui se déploient dans un même espace-temps pour

\footnotetext{
${ }^{30}$ bid., p. 9.
} 
créer un événement performatif unique qui implique nécessairement et simultanément les acteurs et les spectateurs.

L'interartistique met ainsi l'accent sur la dynamique à la fois relationnelle et différentielle qui caractérisait l'art contemporain, et plus précisément la scène contemporaine: les arts entreraient davantage en interaction, croiseraient des territoires, des pratiques, des pensées et des formes de représentation, sans nécessairement que ces processus relèvent de la synthèse ou du mélange. En effet, le préfixe « inter » signifie " être-entre », soit se situer au milieu de deux éléments. Mais cet « être-entre » renvoie aussi bien à la distance entre ces éléments (ou lieux) qu'à la différence (qualitative). Il désigne également, et en même temps, le fait d'être présent dans la relation : inter-esse suppose « $[\ldots]$ une présence aux autres, voire la présence première des autres qui donne au sujet sens et valeur dans l'événement qui les réunit $»$. C'est en vertu de tous ces sens qu'on peut dire des pratiques de l'interartistique qu'elles mettent en jeu des rencontres, des dialogues, des tensions oppositionnelles entre des langages artistiques porteurs d'altérité, à l'intérieur d'un événement qui les réunit sans les confondre ${ }^{31}$.

Enfin, et tel que d'autres disciplines artistiques l'ont vécu précédemment, le théâtre subit actuellement de nombreuses mutations esthétiques qui l'hybrident ả son tour. Ce n'est donc pas un hasard si des concepts issus des arts plastiques, de la musique, de la danse, de la littérature, du cinéma ou de la philosophie caractérisent les pratiques du thêâtre contemporain. De même qu'on peut dire qu'au contact de la performance, le thêâtre se transforme structurellement, se vivifie et s'enrichit infiniment. Josette Féral résume très bien les lignes de force qui s'activent:

[...] deux idées forces sont au cour de l'œuvre performative. D'une part, son événementialité (" it happens », dî Schechner). Elle prend place dans le réel et

\footnotetext{
3! Marie-Christine Lesage dans son excellent article, "L'interartistique : une dynamique de la complexité » in Registres/13, "Théâtre et interdisciplinarité 》, printemps 2008, Presses Sorbonne Nouvelle, Paris, p. 21-22 qui renvoie à son tour à celui d'Eric Méchoulan, qui ouvre tous les sens du préfixe "inter », dans " Intermédialités : le temps des illusions perdues », in Intermédialités, $n^{\circ} 1$, printemps 2003 , p. 11 .
} 
souligne cette même réalité dans laquelle elle s'inscrit en la déconstruisant, en jouant avec les codes et les compétences du spectateur [...] D'autre part, la mise en échec de la représentation. En effet, dans les mises en situation que les spectacles performatifs installent, c'est l'interrelation qui lie le performer, les objets et les corps qui est première. [...] Il s'agit donc d'instituer la pluralité au cœur du processus scénique. L'écriture scénique n'y est plus hiérarchique et ordonnée; elle introduit l'événement, reconnaît le risque. Plus que le théâtre dramatique, et comme l'art de la performance, c'est le processus plus encore que le produit que met en scène le théâtre performatif ${ }^{32}$.

L'acte performatif se dresse donc contre une théâtralité de la représentation mimétique qui crée des systèmes et une unité de sens. C'est ainsi que l'histoire (avec ses personnages qui agissent en fonction de la psycho-logique de la narration) n'est plus depuis longtemps, en fait, depuis Alfred Jarry (Ubu Roi, 1896) et Gertrude Stein, en passant par Samuel Beckett jusqu'à Valère Novarina ou Normand Chaurette, au cœur de l'œuvre.

Là où la théâtralité est davantage liée au drame, à la structure narrative, à la fiction, à l'illusion scénique qui éloigne du réel, la performativité (et le théâtre performatif) insiste davantage sur l'aspect ludique des discours sous ses multiples formes visuelles ou verbales : celle du performeur, du texte, des images ou des choses. Elle les fait dialoguer ensemble, se compléter et se contredire tout à la fois $[\ldots]^{33}$.

De plus, Chantal Pontbriand montre bien que les notions de performance et de processus ont contribué à changer considérablement le sens du temps et de l'espace dans l'art de ce siècle et ont amené avec elles une compréhension différente de l'art et du monde. Ces notions contribuent à la décomposition critique du code théâtral et à l'exploration des

\footnotetext{
${ }^{32}$ Josette Féral, «Entre performance et théâtralité : le théâtre performatif », in Théatre/Public «L'avant-garde américaine et l'Europe, 1. Performance $», n^{\circ} 190,2008$, p. 30.

${ }^{33}$ Ibidem
} 
intersections des différents langages qu'il intègre pour se réinventer. Elles font ainsi écho à l'appel de renouveau du code théâtral qu'Antonin Artaud faisait déjà dans Le Théâtre et son double en 1935. Un renouveau qui pourra capter la vie: une expérience productrice d'un nouvel espace basé sur une idée du temps réel et non fictif.

L'effet de flux constant engendré par les nouvelles œuvres a éloigné l'art de la représentation pour montrer ce qu'il y a d'irreprésentable : soit l'entre-deux des choses, ce qui se passe, ce qui transite dans notre appréhension de la vie, ce qui souvent demeure infixé, ou infixable par les moyens traditionnels de visualisation et de représentation. [...] Les nouvelles formes d'art nous laissent voir l'entre-deux, l'espace entre, l'espace sans nom ${ }^{34}$.

L'ensemble des repérages que je viens d'exposer me permet de faire apparaitre la filiation qui m'autorise à formuler plus précisément ma problématique sur le plan d'une dramaturgie de l'espace au théâtre et à relever un certain nombre de notions et procédés qui me seront utiles pour faire valoir une conceptualisation de la mise en espace au théâtre comme une pratique interdisciplinaire et hétéromorphique. En ce sens, la réflexion d'Hervé Guay dans ce qu'il appelle le dialogisme hétéromorphe est constitutive et essentielle à l'appréhension de mon approche. D'un côté, il valorise une dynamique de la complexité entre les différentes composantes scéniques où la synthèse disparaît « au profit d'une perception ouverte, éclatée, fragmentée plutôt que l'approche uniformisante et globalisatrice ${ }^{35}$ » du thêâtre dit dramatique. De l'autre, il replace le théâtre comme médium dans le sens où l'événement théâtral engage une interaction critique et ludique avec le

\footnotetext{
${ }^{34}$ Chantal Pontbriand, « Notions de performance » in Fragments critiques (1978-1998), Nîmes, Éd. Jaqueline Chambron, coll. « Critiques d'Art », 1998, p. 19-33.

${ }^{35}$ Hans-Thies Lehmann, Le Théatre postdramatique, Paris, L'Arche, 2002, p. 129.
} 
spectateur. Le théâtre performatif se déploie alors dans une dynamique de transgression des genres qui combine les forces, juxtapose les actions, dans une « $[\ldots]$ abondance simultanée de signes comme une redondance à la réalité; elle semble singer l'imbroglio de l'expérience réelle quotidienne $e^{36} \gg$. Dès lors, dans la partie suivante, j'explorerai différents paradigmes qui me permettront de tendre vers une conceptualisation de l'espace au théâtre conçu comme un opérateur intermédial de rencontres singulières dans la différence, la complicité et/ou le conflit.

${ }^{36}$ Ibidem 


\section{CHAPITRE II}

L'ESPACE AU THÉÂTRE : UN OPÉRATEUR INTERMÉDIAL DE RENCONTRES HÉTÉROMORPHIQUES

DU DÉPLOIEMENT INTERDISCIPLINAIRE QUI DYNAMISE LA RENCONTRE AVEC L'AUTRE 
"Le théatre est un art de l'espace et c'est en pesant sur les quatre points de l'espace qu'il risque de toucher

la vie. C'est dans l'espace hanté par le théatre que les choses trouvent leurs figures, et sous les figures le bruit de la vie. Il y a un mouvement aujourd'hui pour séparer le théatre d'avec tout ce qui n'est pas l'espace, et pour renvoyer le langage du texte dans les livres d'où il n'aurait pas dû sortir. Et ce langage de l'espace à son tour agit sur la sensibilité nerveuse, il fait mûrir le paysage déployé au-dessous de lui. Je n'ai pas à refaire ici cette théorie du théâtre dans l'espace, et qui agit à la fois par le geste, par le mouvement, et par le bruit. Occupant l'espace il traque la vie et la force à sortir de ses repaires. ${ }^{37}{ }^{3}$.

Cette partie consiste à développer une articulation théorique qui soutient la poursuite de ce processus de construction par conjonctions rhizomatiques ${ }^{38}$. Ce principe d'écriture me permet de penser la mise en espace comme une pratique interdisciplinaire et hétéromorphique qui dynamise la rencontre avec l'Autre «- face à nous comme en nous car la rencontre n'est possible que dans la différence $-{ }^{39} »$. Pour ce faire, je présenterai quelques-uns des différents changements de paradigme qu'a introduit le théâtre performatif, en l'occurrence, le passage à l'événement, la dynamique de la complexité engendrée par l'interdisciplinarité, le dialogisme hétéromorphe, la notion de dispositif et j'ajouterais les hétérotopies. Ces nouvelles perspectives renouvellent et transforment les interactions avec le spectateur et aident à appréhender quelques-unes des redéfinitions de la pratique théâtrale contemporaine. En outre, je souhaiterais montrer que la position revendiquée qui consiste à

37 Antonin Artaud, « Messages révolutionnaires », op.cit. p. 703. N'oublions pas qu'Artaud a conduit une expérimentation théâtrale d'une extrême radicalité en redéfinissant notamment l'espace scénique à travers l'espace du corps et en proposant dès 1935, dans Le Théatre et son double, la suppression du cloisonnement scène-salle.

38 "Pour des réalités dans lesquelles les ramifications indécryptables ou des conjonctions hétérogènes empêchent la synthèse, Gilles Deleuze et Félix Guattari ont inventé le concept de « rhizome ». Le théâtre lui, a développé un grand nombre de conjonctions rhizomatiques de l'hétérogène ». Hans-Thies Lehmann, op.cit. p. 142 .

39 Daniel Vander Gucht, Ant et politique Pour une redéfinition de l'art engagé, Éditions Labor, coll. « Quartier Libre », Bruxelles, 2004, p. 12. «De même, sì l'art consiste à cultiver la singularité, c'est sans doute le meilleur moyen de pouvoir engager un dialogue avec l'Autre - face à nous comme en nous - car la rencontre n'est possible que dans la différence - l'identique n'engendrant que l'indifférence ». 
questionner la notion de représentation dans une société du spectacle m'amène à déterminer autrement la pratique scénique au théâtre : d'une part, il m'apparât que la dénomination de mise en scène convient désormais bien mal pour décrire comment ces nouveaux paradigmes opèrent dans la création théâtrale et d'autre part, cette même dénomination témoigne de façon déficiente des visées esthétiques et sociopolitiques qui animent plusieurs créateurs. Par conséquent, $j$ 'aimerais soumettre une approche conceptuelle qui mettrait en valeur non plus seulement la fonction scénographique, voire technique de l'espace, mais qui le ferait advenir comme médium, comme un champ d'écriture(s) plus libéré. L'espace apparait alors comme un opérateur intermédial de premier ordre, un détonateur de liberté conceptuelle qui permet des déploiements interdisciplinaires, hétéromorphiques et interrelationnels inédits. En ce sens, la dénomination mise en espace ne vaudrait-elle pas mieux pour traduire la nature de certaines pratiques théâtrales contemporaines ? Celles qui mettent en place un certain nombre de stratégies et de protocoles qui visent à construire une situation pour rencontrer l'Autre ${ }^{40}$, le mettre à l'épreuve de manière ludique et critique afin de réactiver les sensations propres à son être au monde, à la coprésence et à l'être-ensemble. À cet égard, le théâtre me semble le lieu, le médium tout désigné pour mener ces explorations qui sont à la fois théoriques et pratiques.

\footnotetext{
40 Piere Ouellet décrit les ressorts de cette notion polysémique d'altérité dans son introduction « Le principe d'altérité ", dans Quel Autre? : L'altérité en question, sous la dir. de Pierre Ouellet ef Simon Harel, Montréal, VLB éditeur \& Le soi et L'autre, 2007. Autant que faire se peut, je souhaite embrasser ce principe dans toutes ses acceptions : « L'autre est à la fois l'étranger plus ou moins exclu, dominé ou minorisé, pour une large par des études culturelles (de Said à Spivak), l'un des pôles de la construction identitaire pour certaines théories du sujet (chez Ricoeur, notamment), l'expression même de la Loi et du Symbolique pour d'autres (chez Lacan, exemplairement), la figure emblématique de la responsabilité pour une certaine pensée éthique (chez Lévinas, entre autres), le fondement même de route relation intersubjective (chez Husserl déjả) et de tout dialogisme comme de toute énonciation (pour Bakhtine et pour Benveniste) ou, plus radicalement encore, la nature essentiellement hétérologique de l'existence (chez Bataille et ses héritiers). Chaque fois, ce qui est en jeu concene nos manières de vivre-ensemble (le politique) et nos façons de faire, de produire et de créer, notamment par et dans le langage (le poiétique) ». P. 7-8.
} 
Depuis longtemps déjà, ế malgré son caractère éphémère, la mise en scène est considérée comme une pratique artistique spécifique, un art de la pratique scénique qui vise à mettre en cuvre tous les moyens scéniques pour représenter une fiction, essentiellement commandée par la logique d'un texte écrit et la lecture d'un metteur en scène. Les dispositifs théâtraux contemporains de nature interdisciplinaires ont considérablement changé les paramètres de ce théâtre traditionnel ${ }^{41}$ et ont introduit de nouveaux paradigmes qui remettent en cause la mise en scène conçue comme l'orchestration d'un spectacle cohérant qui forme un grand tout monologique et univoque. Le théâtre contemporain produit désormais des univers théâtraux complexes qui ne peuvent plus se résumer à ce type d'approche totalisante.

L'interdisciplinarité, la multidisciplinarité, tout comme l'intermédialité, sont des termes de plus en plus courants, qui témoignent d'une tentative de désigner des créations artistiques polymorphes que l'on peine à enclore dans un seul champ artistique. La scène théâtrale contemporaine participe de cette ouverture des pratiques artistiques entre elles, qui vient accentuer la mixité d'un art déjà « singulier pluriel » [Nancy, 1996] Nomades, ces formes scéniques explorent l'ailleurs en se déterritorialisant. Mais comme on ne se déplace que par rapport à un lieu connu et commun, à un ancrage identitaire si l'on veut, ce décloisonnement, loin de dévoyer le théatre - ou l'idée qu'on s'en fait - permet de faire vibrer en d'infinies variations la théâtralité, afin d'en ouvrir l'événementialité pour le spectateur ${ }^{42}$.

C'est ainsi qu'on assiste au déplacement, déterminant pour l'esthétique théâtrale contemporaine, de l'œuvre à l'événement. La nature processuelle et interdisciplinaire qui

\footnotetext{
${ }^{41}$ Si ce théatre traditionnel reste polymorphique, il se veut avant tout « une synthèse de tous les arts » comme le voulait Wagner. On peut à ce titre se référer à l'ouvrage de Timothée Picard, L'art total. Grandeur et misere d'une utopie (autour de Wagner), Rennes, Presses Universitaires de Rennes, coll. "Aesthetica », 2006.

${ }^{42}$ Marie-Christine Lesage, op.cit. p. 11.
} 
structure le théâtre contemporain le consacre désormais comme un art de l'événement par excellence. Ces pratiques, constiturives de l'activité théâtrale, se déploient dorénavant dans une dynamique de la complexité qui sollicite plus activement la dimension interhumaine ${ }^{43}$ au théâtre. En ce sens, Marie-Christine Lesage montre bien comment l'interdisciplinarité est une ouverture à l'altérité artistique et à l'accroissement de pratiques collaboratives inédites.

[...] l'invitation, qui appelle la rencontre, ne cherche pas l'union mais une sorte de dialogue permettant d'explorer tant les affinités que les écarts entre le théâtre et d'autres pratiques artistiques. II n'y a pas effacement des différences pour l'édification d'un sens commun, mais travail dans la différence. [...] l'alliage de l'hétérogénéité de chaque art (sa différence radicale et exclusive : ce qui définit traditionnellement son genre ou sa discipline) et de leur proximité, des rapprochements, des transferts qui peuvent advenir dans les interrelations provoquées par les invitations et ouvertures artistiques ${ }^{44}$.

Plusieurs créations théâtrales contemporaines se déploient dans des dynamiques de la complexité et de l'entre-deux (à la fois relationnelle et différentielle). Elles font même écho à la pensée complexe développée par Edgard Morin ${ }^{45}$, qui « se moque des chapelles,

4.3 On peut s'inspirer de l'article du sociologue Gérard Donnadieu, «La communication inter-humaine » (2003). Il montre que la nouvelle théorie en communication met en exergue, dans tout échange humain, la primauté de la relation sur le message. Il définit la dynamique relationnelle comme communication interhumaine qui représente ce qui existe au monde de plus complexe. Une approche qui ne se veut pas réductionniste et au contraire, montre la nécessité de rendre complexe notre rapport au monde. Cette même complexité génère de nouvelles formes de réceptions au théâtre. http:/www.arscet.asso.fr/pagesperso/Donnadieu.html (consulté le 10/08/2010)

${ }^{44}$ Marie-Christine Lesage, op.cit. p. 30.

${ }^{45}$ Le Monde//Hors Série, coll. «Une vie, une cuvre. Edgard Morin, Le philosophe indiscipliné », Paris. À partir du portrait brossé par Nicolas Truong, «Itinéraire d'un penseur sans frontières », p. 7-20. 
se méfie des carcans disciplinaires qui cloisonnent et arraisonnent les dissidences ${ }^{46} \gg$, refuse ce qui isole et enferme, et privilégie toutes sortes de stratégies de métissage qui favorisent, dit-11, le décloisonnement et l'ouverture d'esprit. Considérant qu'il estime qu'il n'y a pas de vérité du monde comme un Tout et que la totalité est toujours inachevée, morcelée, fragmentée, la méthode de connaissance qu'il a développée vise à prendre en compte la complexité du réel.

La Méthode identifie trois principes: le "principe dialogique », qui « unit deux principes ou notions antagonistes, qui apparemment devraient se repousser l'un l'autre, mais qui sont indissociables et indispensables pour comprendre une même réalité »; le "principe hologrammique », qui montre que la partie est dans le tout et le tout à l'intérieur de la partie, comme la totalité du patrimoine génétique est contenu dans chaque cellule individuelle; et enfin le "principe de récursion organisationnelle », «boucle génératrice dans laquelle les produits et les effets sont eux-mêmes producteurs et causateurs de ce qui les produit ». Ces principes forment les trois piliers de la «pensée complexe ${ }^{47}$ ».

Sur le plan théâtral, Marianne van $\operatorname{Kerkhoven}^{48}$ souligne pour sa part que les nouveaux langages théâtraux se déploient d'une manière telle, que l'on pourrait établir un rapport avec «la théorie du chaos qui prétend que la réalité consiste davantage en des systèmes instables que dans des circuits hermétiques $[\ldots]$ ». On sacrifie alors la synthèse afin de permettre un renouvellement des formes de la théâtralité comme pratique vivante en prise avec la réalité qui se complexifie et se densifie notamment par la présence plurielle, simultanée et déhiérarchisée d'un faisceau de signes hétérogènes. Nous sommes passés de la perspective euclidienne focale et homogène, propre à une conception univoque du

\footnotetext{
${ }^{46}$ Nicolas Truong, op.cit. p. 15.

47 bid., p. 19.

48 Dramaturge très engagée pour le nouveau théâtre en Belgique avec son essai « Le poids du temps». Citation tirée de H.T. Lehmann, op.cik. p. 130.
} 
monde, aux perspectives plurielles, voire fractales, propres à l'hétérogénéité et l'équivocité du réel. Il va sans dire que l'ambiguïté constitutive d'une ouvre ouverte engage le spectateur dans un processus communicationnel qui l'oblige à créer librement ses propres mizomes de confluences pour structurer ses interprétations. Soulignons néanmoins que l'artiste peut concevoir " une forme chaotique fortement enchâssée dans un vouloir-dire signifiant ${ }^{49} \gg$, une intention, qui recèle non seulement un large éventail de possibilités interprétatives mais aussi, et peut-être surtout, qui convoque l'Autre dans les formes sensibles de l'expérience humaine pour raviver notre présence, notre écoute dialogique à soi, aux autres et au monde environnant.

L'article d'Hervé Guay sur la notion de dialogisme développée par Mikhaël Bakhtine, montre bien comment le théâtre subit de profondes mutations qui le distancient définitivement du modèle dialogique spectaculaire traditionnel, clos en lui-même, et engage un nouveau partage de voix ${ }^{50}$ qui instaure des interactions dialogiques entre plusieurs voix singulières et autonomes, en réservant notamment une place de choix au spectateur.

[...] le théâtre est passé d'un modèle dialogique dominé par la figure de l'auteur, puis du metteur en scène, à un dialogisme hétéromorphe qui fait place à une pluralité de

\footnotetext{
${ }^{49}$ Roger Chamberland, «Oralité protéifome » in Oralités - Polyphonix 16 《a pensée se fait dans la bouche 》), Québec, Les Editions Intervention \& CRELIQ, 1992, p. 9.

50 Jean-Pierre Sarrazac, «Le partage des voix », in Nouveaux territoires du dialogue, sous la dir. de JeanPierre Ryngaert, Arles, Actes Sud-Papiers/CNSAD, coll. « Apprendre», 2005, p. 11-16.

Il indique que le titre de son article provient de l'expression tirée d'un Iivre de Jean-Luc Nancy, Le Partage des voix, Galilée, «Débats », 1982. Dans cet article, il souligne que « (...) le dialogue n'est plus ce dialogue latéral confiné sur la scène entre les personnages; il s'élargit considérablement tout en devenant hétérogène et multidimensionnel - Bakhtine dirait qu'il se dialogise ».
} 
voix et de langages. Dans cette perspective, beaucoup de créateurs contemporains préfèrent se centrer davantage sur les interactions qui se nouent avec les diverses composantes de l'événement théâtral et sur la relation spécifique à instaurer avec le public plutôt que sur les échanges des personnages. Le caractère interhumain propre à l'événement théâtral apparaît donc transformé, puisque le processus collectif de la fabrication de spectacle est mis en évidence dans la représentation elle-même ${ }^{51}$.

Ce nouveau dialogisme métamorphose la manière dont le spectateur perçoit l'événement théâtral puisqu'il se trouve mis en présence de plusieurs énonciateurs qui déclinent autant de points de vue et d'angles d'attaques singuliers. Ces propositions s'additionnent, se juxtaposent, se contredisent ou convergent, pour créer un concert complexe qui instaure une dynamique communicationnelle irréductible à l'unité de la raison ou du sens. Ces nouveaux rapports dialogiques de nature hétéromorphique supposent une expérience fertile de coprésence et une coélaboration qui engage le spectateur à composer son propre ensemble de manière ludique et critique dans le cadre d'une activité collective.

On voit bien que le théâtre n'est plus le domaine institutionnalisé qu'il était - « sous peine de devenir un musée de la représentation » dira même Frank Bauchard ${ }^{52}$-, mais le lieu où l'on peut même actualiser des concepts philosophiques, comme les notions de déplacement, déconstruction, dissémination de Derrida, d'hétérotopie de Foucault, de pensée complexe de Morin, du rhizome de Deleuze et Guattari, de la phénoménologie de la

\footnotetext{
${ }^{51}$ Hervé Guay, «Vers un dialogisme hétéromorphique », in Tangence, $\mathrm{n}^{\circ}$ 88, automne 2008, p. 63.

52 Frank Bauchard, "Esthétiques des mutations scéniques », in Études théâtrales, Ants de la scène, scène des arts, $n^{\circ} 28$ \& 29, 2003-2004, vol. II "Limites, horizon, découvertes: mille plateaux », Louvain-la-Neuve, (Belgique), p. 131.
} 
perception de Merleau-Ponty, par une pratique artistique interdisciplinaire et hétéromorphique de mise en espace. Elle se présente donc comme une audace artistique qui se manifeste dans l'écart et la distanciation par rapport à la dramaturgie (scénique) afin de concevoir un événement éphémère interhumain, interactif et ludique. En fait, je pense qu'on peut même aller plus loin en défendant que le théâtre est un médium exceptionnel pour questionner et expérimenter diverses théories et pratiques si on considère enfin l'espace pour ses qualités intermédiumiques, apte à générer des rencontres hétéromorphiques. Le théâtre devient alors un «tissu conjonctif » dira Loubier ${ }^{53}$ ou un « indispensable miroir critique » de la scène virtuelle dira Bauchard ${ }^{54}$.

Aussi, la proposition d'Amaud Rykner d'interroger la notion de dispositif au théâtre contribue à enrichir cette réflexion. Il indique qu'il y a trois aspects majeurs qui déterminent la nature d'un dispositif: la dimension spatiale d'organisation de l'espace par opposition au domaine de la scénographie; la dimension dynamique et relationnelle avec le corps spectatorial et enfin, la proposition d'une « structuration symbolique du monde ${ }^{55}$ ». Des conditions qui sont de nature à éveiller notre existence à sa dimension spatiale (dans le sens où elle est située et orientée dirait Merleau-Ponty ${ }^{56}$ ), permettant ainsi de faire voir ce

\footnotetext{
${ }^{53}$ patrice Loubier cité par Marie-Christine Lesage, op.cit. p. 21.

${ }^{54}$ Frank Bauchard, op.cit. p. 131.

${ }^{55}$ Arnaud Rykner, « Du dispositif et de son usage au théâtre », Tangence, $n^{\circ} 88$, automne 2008, p. 98.

${ }^{56}$ Dans la Phénoménologie de la perception, Paris, Gallimard, coll. « Tel », 1945, p. 291. Merleau-Ponty montre que l'existence est spatiale au sens où « notre rencontre primordiale avec l'être » est d'emblée « situee » et « orientée ». « Tout nous renvoie aux relations organiques du sujet et de l'espace, à cette prise du sujet sur son monde qui est à l'origine de l'espace $»$.
} 
qu'il y a autour de soi, d'activer tous les sens du spectateur pour renouveler son rapport à l'être.

Le théâtre du dispositif [...] manifeste le caractère primaire de la représentation, qui dispose avant d'en imposer [...] qui se contente d'organiser dans l'espace de la représentation. Il le rend pour ainsi dire habitable, sans chercher à lui donner un sens immédiat. Aux signes décodables de la représentation classique, le dispositif tend ainsi à préférer une certaine opacité du visible: le spectateur entre dans un espace sémantiquement ouvert, plutôt que de se voir proposer les clefs qui lui permettront de comprendre ce à quoi il va assister ${ }^{57}$.

Contrairement à l'espace dramatique traditionnel qui se construit par une scénographie qui dénote les significations majeures de la représentation et qui tient le spectateur à distance, le dispositif, lui, se fonde sur une forme d'inclusion du corps spectatorial comme constitutif même du dispositif. Le spectateur entre et le dispositif agit alors comme un révélateur.

La deuxième caractéristique majeure du dispositif, qui l'arrache au seul domaine de la scénographie suppose l'implication de ceux par qui autant que pour qui il est institué : il tire ses effets de la façon dont tous les actants, à commencer par les spectateurs auxquels il est destiné, l'investissent d'un point de vue physique, psychologique et/ou cognitif ${ }^{58}$.

Ainsi, à l'opposé de la conscience épique qui suppose que le sens soit développé en amont de la scène par le metteur en scène, le dispositif postule que l'élaboration du sens

\footnotetext{
${ }^{57}$ A. Rylkner, op.cit. p. 93

58 Ibid., p. 94.
} 
relève d'un processus continuel et non d'un système ou d'une structure ${ }^{59}$. Les significations ne sont plus ordonnancées et transmises; elles sont développées autant individuellement que collectivement. Rykner précise qu'il n'est nullement nẻcessaire de faire bouger le public, de le forcer d'aller d'un point à l'autre pour établir le dispositifo : la liberté d'aller suppose aussi celle de ne pas bouger (tout en participant à l'élaboration de l'œuvre), car l'immobilité n'empêche nullement l'ouverture psychique des espaces. La démarche de Claude Régy est, en ce sens, exemplaire de cette réflexion et de cette pratique puisque sans remettre en cause les dispositifs de frontalité, il arrive à remettre en jeu une certaine lecture du monde: «Notre souci, ce devrait être, il me semble, comment amener chacun à renouveler, lui-même, de façon autonome, sa sensation du monde ${ }^{61}$ ». Enfin, conjugué à ces deux caractéristiques (organisation spatiale et interactions entre le public et le spectacle), le dispositif doit pouvoir créer un effet d'expansion symbolique qui permet d'échapper à la vacuité d'un formalisme pur et dur et qui favorise l'émergence de conditions pour qu'advienne un Partage du sensible ${ }^{62}$.

Rykner souligne aussi le travail de François Tanguy et du Théâtre du Radeau pour illustrer le rôle prépondérant du dispositif dans la création contemporaine. Il relate que

\footnotetext{
59 Toutefois je pense que l'on peut, à la manière de Régy, anticiper l'élaboration de sens pour générer des perceptions particulières. La réception est plus ouverte c'est vrai, mais néanmoins élaborée en amont.

${ }^{60}$ En ce sens, ma proposition de création déambulatoire ne représente qu'une traduction possible du dispositif tel que Rykner l'expose.

${ }^{61}$ Claude Régy, Espaces perdus, Besançon, Les solitaires intempestifs, 1998, p. 83. Ce « comment amener » montre bien qu'il y a une volonté d'élaborer un sens à son écriture, même sì c'est́ pour mieux créer un relâchement de sens (donc une équivocité) chez le spectateur.

${ }^{62}$ En référence au livre de Jacques Rancière, Le Partage du sensible. Esthétique et politique, Paris, la Fabrique, 2000.
} 
depuis les années 1990, Tanguy n'a pas cessé de proposer des dispositifs qui aidaient le spectateur à renouveler les conditions de sa propre perception du monde et l'amenait à formuler une théorie nouvelle et personnelle du réel. Son travail permet de comprendre la mobilité et la malléabilité de la plasticité du dispositif ${ }^{63}$, autant dans son rapport aux arts plastiques, que de saisir la richesse de l'usage qu'on peut en faire.

[...] loin de privilégier un matériau à un autre (texte, image, musique, danse, etc.), il les fait coexister; loin de se contenter de les juxtaposer, il les fait s'entrechoquer pour créer un nouvel espace de visibilité et d'écoute; loin de se borner à l'une des trois dimensions du spectacle (technique : les jeux de la scène; pragmatique : la captation du public et l'échange avec celui-ci; symbolique : le jeu sur le sens), il vise à les articuler en un processus continu et ouvert, et non un système cohérent mais fermé. En organisant l'espace autrement, il permet au spectateur d'y « creuser son trou »; en le laissant circuler à l'intérieur de sens toujours en émergence, sans lui imposer ces derniers, mais également sans l'en priver, il propose de nouvelles modalités du réel qui ne sont ni des valeurs prédéfinies, mais impossibles à actualiser, ni des formes vides, ni des formes-sens définitivement bloquées ${ }^{64}$.

L'exemplarité du travail de Tanguy et du Théâtre du Radeau permet de décliner toutes les richesses que recèle le dispositif grâce à sa nature essentiellement spatiale et plastique. De plus, la prise en compte de la dimension nécessairement interactive et subjective de la réception contribue à façonner une expérience esthétique qui fait (ou qui défait) et fait faire ${ }^{65}$. L'expérience esthétique se révèle ainsi comme une constante

\footnotetext{
${ }^{63}$ Ma proposition déambulatoire pourra peut-être aussi contribuer à faire saisir la polyvalence de ce concept puisque je présenterai quatre dispositifs complètement différents.

64 Amauld Rykner, op.cit. p. 100.

${ }^{65}$ Jocelyne Lupien, «Sensation, perception, représentation: l'art comme expérience sensible », in Énonciation artistique et socialité, Paris, L'Harmattan, coll. « Logiques sociales », p. 47-49.
} 
transaction entre «l'en-soi cosmique et le pour-soi subjectif ${ }^{66} »$ dirait Guattari. Elle doit se comprendre comme une expérience éminemment personnelle qui se transige en relation avec les valeurs communes, sociales et collectives. En ce sens, le travail de recherche mené par Jocelyne Lupien démontre que la dimension polysensorielle des formes d'expression artistique est de nature à favoriser une réception qui agirait « comme "déverrouilleur" des sens en tant que moyen, pour les spectateurs, non seulement de prendre conscience de leur condition de sujet percevant mais aussi de leur position en tant que sujet politique dans le monde ${ }^{67} \gg$.

Aussi pour compléter cette deuxième partie, le concept de mise en espace me permet de concevoir et de proposer des espaces d'expérimentation proches de la notion d'hétérotopie ${ }^{68}$, développée par Michel Foucault. Rappelons que cette notion vise essentiellement à décrire un lieu radicalement «autre » mais réel, inscrit dans l'espace social, « une espèce de contestation à la fois mythique et réelle de l'espace où nous vivons ${ }^{69}$ », un « ailleurs » incarné, « sortes d'utopies effectivement réalisées », qui place les individus dans un espace où la rupture avec l'espace habituel se double d'une rupture avec le temps traditionnel (hétérochronie). On entre alors dans une catégorie singulière de rapport aux espaces-temps qui broulle les frontières usuelles (hors lieux pourtant

\footnotetext{
${ }^{66}$ Félix Guattari, «L'oralité machinique et l'écologie du virtuel 》, in Oralités-Polyphonix 16 « La pensée se Fait dans la bouche », Québec, Les Éditions Intervention \& CRELIQ, 1992, p. 25-32.

67 Jocelyne Lupien, op.cit. p. 49.

${ }^{68}$ Michel Foucault, Dits et écrits II 1976-1988, «Des espaces autres », Paris, Gallimard, coll. « Quarto », 2001, p. $1571-1581$.

${ }^{69}$ Ibid., p. 1575.
} 
localisables, hors temps singulier et très sensible), comme un voyage en bateau ou une visite au musée ou à la bibliothèque. Il s'agit donc de lieux bien réels, au cœur desquels un dispositif engendre un nouvel ordre symbolique qui crée du décalage et de la discontinuité avec les normes de la vie ordinaire. C'est « un lieu autre par rapport aux espaces culturels ordinaires $^{70} \gg$ qui fait que nos repères, nos jugements, notre perception ordinaires vacillent et sont remis en question. "Des espaces [hétérotopiques] qui n'identifient pas, qui ne produisent aucune identité fuxée de l'être mais qui engendrent au contraire une transformation, une expérience transformatrice qui met en mouvement ${ }^{71} \gg$. Des espaces qui façonnent le paysage d'un ensemble de relations qui, elles-mêmes sont, en quelque sorte, des contre-espaces de la vie quotidienne, « des utopies localisées » qui ritualisent les ruptures, les seuils, les crises et qui permettent des moments de déviation où la mise à l'épreuve de nos schémas perceptifs et mentaux et l'expérience sensorielle sont stimulées.

En résumé, il me semble important de revoir en quoi les diverses interconnexions rhizomatiques que je viens de tisser m'autorisent à considérer le concept de mise en espace comme une pratique théâtrale à part entière et non seulement comme une simple désignation. J'estime en effet que l'espace est un opérateur intermédial qui dynamise la rencontre avec l'Autre et qui favorise l'avènement de cet événement dans toutes ses potentialités. De plus, je considère que l'interdisciplinarité engendre une dynamique de lâ complexité, à la fois relationnelle et différentielle, qui permet l'amorce d'un processus d'écriture hétéromorphique (composé de différentes stratégies énonciatives) qui se déploie

\footnotetext{
${ }^{70}$ Michel Foucault, op.cit. p. 1576.

${ }^{71}$ Ibidem
} 
dans l'espace d'un dispositif conçu pour créer des hétérotopies, comme autant d'espaces autres, échafaudées dans le but de construire des situations ludiques de rencontre avec l'Autre pour ouvrir et mettre à l'épreuve l'être au monde, la coprésence, l'être-ensemble et le vivre-ensemble ${ }^{72}$. Autant de structurations symboliques du monde qui sont de nature à intensifier le moment présent et à raviver notre présence au monde.

Ces quelques perspectives théoriques et esthétiques permettent de reconsidérer, voire de métamorphoser, la place du public dans le théâtre contemporain. J'oserais dire que dans cette conception, le spectateur passe d'une place de spectre-acteur flors de la conception et de l'élaboration du dispositif de jeu où il est absent et néanmoins éminemment présent puisque c'est une étape où je structure l'être-ensemble) à celle de coacteur qui, par sa participation et sa collaboration à la situation, permet d'engager un processus interrelationnel d'être-ensemble, et de composer une assemblée théâtrale ${ }^{73}$.

Considérant que le théâtre se définit tout en présence et qu'il est essentiellement centré sur la double exigence de la mise en présence des acteurs mais aussi des spectateurs, le concept de mise en espace permet d'envisager cette relation dans une dynamique

\footnotetext{
${ }^{72}$ Il est à noter que le Centre d'Études sur les Letires, les Arts et la Tradition (CELAT) propose pour leur nouveau programme le thème du vivre-ensemble: «Par vivre-ensemble, nous entendons les formes et enjeux de la vie collective découlant de la diversité et du pluralisme, marquant les relations entre les groupes majoritaires et minoritaires ou minorisés et les individus qui les composent, leurs formes de vie et d'expression, leurs langages, leur mémoire et leurs expérimentations \%. Voir le site http:/www.celat.ulaval.ca/index.php (consulté le 10 septembre 2010)

${ }^{73}$ Voir à ce sujet le recueil L'assemblée théâtrale, (sous la coor. de Florence Thomas), Paris, Éditions de l'Amandier, 2002 qui relate les discussions qu'ont eues de nombreux acteurs, sociologues, philosophes et metteurs en scène, lors d'une rencontre organisée à l'initiative d'Alain Françon et de Robert Cantarella.
} 
spatiale, de penser une assemblée et peut-être même de composer une communauté éphémère. Etant donné que chaque texte appelle une certaine façon de spatialiser l'espace, privilégier la réalité d'un espace, au lieu de la notion de décor est une idée banale, mais en réalité très sensible. Je souhaite créer des dispositifs qui demandent au spectateur de réinventer sa place, de façon dynamique, en lui imposant d'oublier la manière de se tenir, de sortir de son siège et de trouver une autre manière de se comporter, en situation de coprésence (avec et devant l'Autre). Je souhaite proposer au spectateur d'expérimenter toutes sortes de situations construites dans le dessein qu'il invente sur le champ une autre possibilité d'être-ensemble. C'est ainsi qu'en transgressant les paramètres de la représentation théâtrale et en brouillant (insidieusement) la répartition spatiale usuelle voulant qu'on sépare le public et les acteurs, le spectateur doit composer avec autant de situations performatives, où la rampe est parfois mise de côté, où l'on est alors ensemble, du même côté (mais avec nos différences), dans un espace aux formes ouvertes.

En outre, la participation sensorielle et performative du spectateur dans l'environnement n'implique pas seulement une inclusion purement spatiale, mais aussi temporelle; elle se déroule dans un temps réel et non fictif. Elle engendre un découpage singulier du temps composé de discontinuités et de ruptures. C'est une œuvre où le processus est tout aussi important que ce qui est montré; il génère même du sens. Mais surtout, l'œuvre permet (en son sein) la rencontre et l'interaction de différents individus qui deviennent, pour ce moment précis, des sujets, acteurs et coacteurs d'un même événement. La mise en espace pourrait se définir comme l'espace-temps d'une expérience, le milieu 
d'une dynamique non seulement perceptive, mais aussi performative et relationnelle. Une expérience hétérotopique et hétérochronique (qui valorise l'ailleurs et le processus temps). Une conception de l'espace qui fonde sa façon de voir, on pourrait même dire de se mouvoir, en opérant un déplacement d'axe de tension : le spectateur n'est plus face à l'objet mais dans l'environnement, y participant, éprouvant du sens par son être au monde (en relation avec l'Autre). Une esthétique de la présence et de la manifestation. Comme le réel qui nous entoure, nous sommes le centre toujours mobile où chacun voit depuis son site ${ }^{74}$. En conséquence, le concept de mise en espace me permet de favoriser la réappropriation d'un corps plus kinesthésique, de convoquer la capacité de voir, d'entendre et d'aviver les formes sensibles de l'expérience humaine.

[...] de façon inédite, chacun est alors attentif à sa propre présence et à celles des autres, à la salle, à la scène, à l'être ensemble qui se déploie dans un processus. [...] Le théâtre devient « situation sociale » dans lequel le spectateur apprend comment ses expériences ne dépendent pas que de lui seul, mais également d'autrui. Dans la mesure où son propre rôle entre en jeu, le modèle fondamental du théâtre peut véritablement s'inverser ${ }^{75}$.

Le théâtre performatif est le lieu d'un rassemblement réel où s'opère un recoupement original entre la vie, à la fois organisée esthétiquement, et celle du quotidien bien réel. Il est composé d'un ensemble de " démarches relationnelles instaurant des rapports

\footnotetext{
${ }^{74}$ Anne Cauquelin, Le site et le paysage, Paris, PUF, coll. « Quadrige», 2002, p. 143-160. Où elle indique notamment qu' "Une série de paradoxes, constitutifs du site, vont lui donner une allure particulière, dont le trait le plus notable est la propriété de « faire voir» ce qu'il y a autour de lui. Et sans doute aussi invite-t-il à aller « ailleurs ».

${ }^{75}$ Hans-Thies Lehmann, op.cit. p. 169.
} 
dialogiques $^{76} \gg$ qui placent le spectateur dans une position de participant au processus de création qui se déploie hic et nunc. Il ne pourra jamais être reproduit de façon identique puisque ce ne sera jamais ni tout à fait le même lieu, ni les mêmes gens, ni tout à fait la même situation. Il est éphémère et se fonde explicitement sur la nature processuelle et interactive de ce moment unique, non reproductible, in actu, comme élément constitutif de l'événement théâtral. Ainsi, de manière générale on peut dire que tout ce que font les acteurs exerce un impact sur les spectateurs, et que tout ce que font, (ou ne font pas) les spectateurs a un impact sur les acteurs et les autres spectateurs. Dans ce sens l'événement n'advient que dans son déroulement même. Il est une expérience de coprésence unique, de collaboration et de coélaboration dans un processus collectif de création du "spectacle". C'est bien en ce sens que les spectateurs jouent un rôle de coacteurs puisqu'ils sont cocréateurs (il n'y a pas de message univoque à recevoir mais une expérience de structuration subjective et intersubjective à vivre). C'est alors seulement que la proposition de création pourra s'achever.

Dans les parties suivantes, je montrerai comment cette filiation historique et ces conceptualisations théoriques cherchent à s'actualiser dans ma démarche de création. Il va sans dire que ces visées animent à la fois ma pratique mais se manifestent aussi dans ma façon de concevoir le travail de collaboration.

\footnotetext{
${ }^{76}$ C'est ce que Fred Forest proclamait déjà dans les années 1970: «l'art se conçoit maintenant comme un ensemble de "démarches relationnelles » instaurant des rapports dialogiques ». Cité d'après Daniel Vander Gucht, op.cit. p. 61.
} 
CHAPITRE III

LA MISE EN ESPACE:

UNE PRATIQUE INTERDISCIPLINAIRE ET HÉTÉROMORPHIQUE 
Il s'agit donc, pour le théâtre, de créer une métaphysique de la parole, du geste, de l'expression, en vue de l'arracher à son piétinement psychologique et humain ${ }^{77}$.

Ce chapitre sera l'occasion de prolonger ma réflexion sur l'espace au théâtre à travers ma démarche pratique. Je souhaite montrer que le concept de mise en espace est non seulement un opérateur conceptuel fertile, mais qu'il représente dans mon processus créatif, un opérateur pragmatique qui catalyse un potentiel interdisciplinaire hors du commun. En effet, la notion de mise en espace permet notamment aux arts plastiques, sonores, médiatiques, ̀̀ la danse, à l'architecture et à quelques pratiques stratégiques de l'espace telles les installations, voire l'installaction, l'art contextuel, l'in situ et le land art, de jouer de leurs influences pour collaborer à réarticuler et à réanimer les paramètres du théâtre dans une dialectique ouverte. L'espace au théâtre que j'explore génère ainsi une dynamique d'action intermédiatique qui met au premier plan non seulement le média, ou les médias, mais bien ce qu'il y a entre les médias. Une approche artistique qui n'est plus, donc, sur la chose (le média), mais sur les relations entre les choses ${ }^{78}$. De même, en m'emparant d'une attitude performative, qui procède de la mise en pratique critique, je tente de questionner, possiblement de renouveler les pratiques et les codes au théâtre dans une perspective exploratoire, dynamique et non synthétique. Mon lieu théâtral devient alors un lieu de recherche et de médiations inouies. I se manifeste dans la force de ses

\footnotetext{
${ }^{77}$ Antonin Artaud, op.cit. p. 558.

${ }^{78}$ Voir le site du Centre de Recherche sur I'Intermédialité (le CRI), http:/cri.histartumontreal.ca
} 
spécificités; un art vivant relationnel, et qui plus est, prend de l'écart par rapport au spectacle.

Bien que l'on considère généralement la mise en espace comme une forme nonaboutie, une esquisse de la mise en scène à venir ${ }^{79}$, j'avance un concept qui se développe comme pratique théâtrale à part entière. La mise en espace offre la dynamique pour déplacer (ou dépasser) la représentation théâtrale vers des événements ${ }^{80}$ interdisciplinaires et hétéromorphes. En fait, je constate que le concept de mise en espace permet de repenser les enjeux et les processus qui sont à l'œuvre dans la création théâtrale contemporaine (incluant les nécessaires va-et-vient entre la théorie et la pratique qui alimentent le travail d'un artiste). De plus, je fais l'expérience qu'il concourt à la déhiérarchisation des signes et à une possible délocalisation des procédés théâtraux traditionnels. Développer une dramaturgie de l'espace au théâtre m'apparaît comme une prise de risque de penser l'espace à la manière d'une rhizomatique structurée de manière hétérogène qui s'articule dans une matérialité (des corps, des gestes, du mouvement, de la parole, du son, de la matière, de la lumière, etc.). Autant d'éléments qui me permettent une écriture ouverte et hétéromorphique qui répond de mes préoccupations et de mes utopies.

\footnotetext{
${ }^{70}$ Patrice Pavis, définit la mise en espace en ces termes: «choix d'options spatiales à la lecture de la pièce et tentatives de les traduire dans les positions et déplacements des acteurs », La mise en scène contemporaine, origines, tendances, perspectives, Paris, Armand Colin, 2007, p. 310.

${ }^{80}$ Néanmoins comme Agamben le précise dans la lignée de Debord, il faut que l'événement se mue en expérience pour celui qui participe, aussi bien l'acteur que le spectateur. G. Agamben, Enfance et histoire, Paris, Petite Bibilothèque Payot, 2002, p. 20-21.
} 
Je cherche à engager un dialogue qui favorise une pratique de l'écart et de la connivence à partir de laquelle peuvent se côtoyer et s'agencer, sans subordination, le jeu et les techniques du son, la danse et la philosophie, ou encore la lumière et le politique. De sorte que l'idée d'un dispositif peut aussi bien naître de la rencontre entre un texte, une conception théorique, une donnée technique ou une image poétique. L'objectif étant de mettre en place un dispositif de jeu interrelationnel qui sera de nature à contextualiser la coprésence et à susciter une participation du spectateur plutôt que de le reléguer à un rôle de contemplation, bref à le rendre coacteur du moment construit, engagé dans un processus qui met en mouvement à travers la psychogéographie ${ }^{81}$ d'un territoire; une dérive, une émanation situationniste. ${ }^{82}$

En m'intéressant à la manière dont le spectateur vit et éprouve le monde, je peux travailler sur les situations d'écoute, provoquer le trouble par rapport au texte et à l'événement en utilisant diverses stratégies énonciatrices. Des protocoles proposés en amont aux acteurs qui deviennent une manière de convoquer symboliquement le collectif à se construire dans une danse, un échange non pas d'acteur à spectateur, mais un échange

\footnotetext{
${ }^{81}$ Selon Guy Debord, «La psychogéographie se proposerait l'étude des lois exackes, et des effets précis du milieu géographique, consciemment aménagé ou non, agissant directement sur le comportement affectî des individus. », Guy Debord, "Introduction à une critique de la géographie urbaine » in Les Lèvres nues, $n^{\circ} 6$, Bruxelles, 1955.

82 «Entre les divers procédés situationnistes, la dérive se présente comme une technique du passage hâtif à travers des ambiances variées. Le concept de dérive est indissociablement lié à la reconnaissance d'effets de nature psychogéographique, et à l'affirmation d'un comportement ludique-constructif, ce qui l'oppose en tous point aux notions classiques de voyage et de promenade $\%$ I.S., op.cit. p. 51.
} 
d'acteur à acteur où chaque acteur se voit en voyant l'autre ${ }^{83}$. Ainsi, il m'apparâ̂t constitutif, sur le plan de l'écriture spatiale, de prendre en compte l'altérité comme fondement de la communauté humaine pour expérimenter, voire partager un processus théâtral à la manière d'une utopie sociale.

La notion de mise en espace me permet donc de convier le spectateur dans une dynamique spatiale qui sollicite immédiatement son implication et sa paricipation. L'espace est alors perçu autrement puisqu'il s'ouvre dans une organisation plus complexe qui introduit plusieurs lignes de fuite. Une situation qui incite le spectateur à être actif dans ses choix de regard et ses points de vue et où il se trouve d'emblée dans un rapport d'expérience plutôt que de connaissance. II n'est pas convoqué pour comprendre, mais bien pour vivre un événement qui se fonde sur un rapport sensible à l'espace et au mouvement. Et c'est d'abord avec son corps que je tente d'instaurer ce dialogue, pour qu'ensuite il mesure et analyse l'écart entre la fonction habituelle d'un lieu et l'usage ludique qu'on peut en faire. À cet égard, Josette Féral apporte une contribution notable consignée dans le livre Théatre : espace sonore, espace visuel ${ }^{84}$. Son analyse permet d'appréhender le potentiel de recherche et d'exploration que recèle notre relation à l'espace. Elle y souligne notamment que l'expérience spatiale au théâtre est̂t un phénomène de polysensorialité « $[\ldots]$ qui renvoie, au-delà des mécanismes perceptifs communs, à la subjectivité de chacun:

\footnotetext{
${ }^{83}$ Bien sûr on peut se référer à l'ouvrage de Georges Didi-Huberman, Ce que nous voyons, ce qui nous regarde, Paris, Edition Minuit, coll. "Critique », 1992. L'auteur part du postulat concernant l'expérience visuelle que ce que nous voyons ne vaut - ne vit - que par ce qui nous regarde.

${ }^{84}$ Actes du colloque de la Fédération internationale pour la recherche thêatrale (FIRT).
} 
subjectivité de la pensée, de la mémoire, de l'imaginaire et, plus encore, subjectivité du $\operatorname{corps}^{85} 》$. En outre, le travail de nombreux chercheurs québécois ${ }^{86}$ montre «qu'un certain théâtre - théâtre d'images, théâtre empruntant aux technologies, aux installations, aux arts plastiques - a effectivement institué une nouvelle sensibilité chez le spectateur ${ }^{87}{ }$.

La mise en espace c'est aussi concevoir et fabriquer un événement de façon à ce qu'll soit traversé par des instants de déviation, de transgression, d'audace et de questionnement qui pourront créer des interruptions dans le quotidien, dans le sens où something happened. Ainsi, en parenté avec le happening et la performance, je choisis d'investir la réalité d'une façon événementielle. Je souhaite faire valoir le potentiel critique, esthétique et ludique d'une pratique plus portée à la présentation qu'à la représentation. Par conséquent, les relations effectives, corporelles et spatiales d'acteurs et de spectateurs me permettent de sonder les possibilités de participation et d'interaction pour accentuer la présence (le faire, ici et maintenant) au lieu de la représentation (la mimesis du fictif et le simulacre), l'acte au lieu du résultat. L'événement s'affirme alors comme un processus, comme une action en train de se faire et non comme un résultat, un objet artistique accompli ou un spectacle. En ce sens, le théâtre performatif ouvre un champ entre

\footnotetext{
${ }^{85}$ Josette Féral, «Un corps dans l'espace : perception et projection », Théatre : espace sonore, espace visuel, (dir.) Christine Hamon-Siréjols et Anne Surgers, Lyon, Presses Universitaires de Lyon, 2003, p. 134.

${ }^{86}$ Il s'agit des travaux de Chantal Hébert et de Marie-Christine Lesage qui portent respectivement sur Robert Lepage et Denis Marleau, le Théâtre UBU et le collectif Recto Verso. Toutefois certaines des conclusions auxquelles elles arrivent s'appliquent parfaitement à Bob Wilson, Tadeusz Kantor, Élizabeth Lecompte, Reza Abdoh ou de Urban Dream Capsule. Soulignons aussi le travail que mènent Irène Perelli-Contos, Pierre Ouellet, Jocelyne Lupien et Roger Chamberland puisqu'ils concourent à ces nouvelles formulations.

${ }^{87}$ Josette Féral, op.cit. p. 141.
} 
(intermédial) qui propose non pas une représentation, mais une approche expérientielle immédiate du réel (espace, temps, corps) qui se manifeste dans un dialogisme hétéromorphique.

Je tiens à faire un théâtre énergétique où les forces en présence excèdent les simples signaux de sens pour ouvrir un champ plus large, un champ libre et polyphonique. Faire voir des états de présence qui ne se basent pas sur la psychologie des personnages à reconstituer. C'est d'ailleurs ce que Jean-François Lyotard ${ }^{88}$ semble déplorer quand il rappelle que toute la théâtralité se conforme au modèle "Fort-Da", remplacementdéplacement de l'objet réel vers sa représentation, alors qu'il rêve, tout comme Artaud, d'un thêâtre énergétique, à la mort du signe mimétique et logocentrique. Une théâtralité đébarrassée de la sémiotique où les signes seraient libres, producteurs de sensations et délivrés du sens, parce que le sens, comme le souligne Barthes, n'est pas au bout du récit, il le traverse. Une forme composée de fragments dont il importe moins de connaitre la finalité que d'en sentir l'essence et le processus de transformation. Un théâtre de la cruauté où le sens est au cour de la sensation et de la fabrication. Un espace d'élaboration du fantasme, soutenu par des énergies covécues et coéprouvées, ressenties comme des forces à l'œuvre qui promeuvent une réception ouverte, résolument personnelle et plurielle.

\footnotetext{
${ }^{88}$ Jean-François Lyotard, Des dispositifs pulsionnels, Paris, Christian Bourgois, coll. «10/18», 1980, p. 88-
} 89. 
Concrètement, j'explore la matérialité de l'espace et de ses signes, pour créer des structures spatiales unifiantes (qui se situent davantage du côté de l'installation, voire de l'in situ) où l'on ressent la matérialité du langage théâtral, par opposition à un lieu neutre, "aseptisé", qui a pour fonction de voir (et d'écouter) un spectacle en toute quiétude. Puisque le théâtre est un lieu physique concret (destiné aux sens, dirait Artaud), je souhaite engager une réflexion et des explorations sensorielles qui proposent des usages inédits de l'espace et du corps par la conception de dispositifs qui engagent des corps vivants et mouvants à se déployer dans l'espace. Un traitement descorps dans une esthétique d'inspiration sculpturale et chorégraphique qui s'affranchit du décor. Ye modifie l'ordonnancement (et donc le déclassement de l'espace classique regardant-regardé) en un espace installatif. C'est ainsi qu'en convoquant le spectateur dans l'espace de jeu, je fais disparaitre le principe de bidimensionnalité, de façade scénographique, de décor figé et (an)esthétisant, de monde séparé ${ }^{89}$, et je mets en jeu le schéma corporel du spectateur. Je l'interpelle comme témoin, participant. L'important n'est pas tant qu'il reconnaisse des lieux réels ou fictifs, mais qu'il se déplace dans des formes et des structures qui rendent l'espace à la fois plus concret et équivoque. Une façon de créer des espaces symboliques qui se matérialisent soit par un aspect de la proposition dramaturgique, ou encore, qui rejouent une structuration symbolique du monde. Autant de manières de soumettre l'espace théâtral à une logique différente pour lui conférer une atmosphère singulière, parfois étrange ou inusuelle.

\footnotetext{
${ }^{89}$ En référence au concept développé par Debord qui annonce la domination du spectacle sur la vie : « L'homme séparé de son produit, de plus en plus puissamment produit lui-même tous les détails đe son monde, et ainsi se trouve de plus en plus séparé de son monde. D'autant plus sa vie est maintenant son produit, d'autant plus il est séparé de sa vie ». op.cit. p. 544.
} 
Afin de mettre en œuvre un certain nombre de données conceptuelles présentées dans ce mémoire, $j$ 'ai eu envie de proposer un projet de création qui n'est pas conçu dans un seul et même espace, mais qui s'actualise comme un cheminement qqui entrâne l'individu dans un processus. En ce sens, le parcours déambulatoire me semble une stratégie particulièrement efficace pour faire ressentir notre relation à l'espace (sur un territoire, ou dans un dispositif donné); mais aussi pour développer quatre dispositifs de mise en espace complètement différents. Considérant « que le sentiment de l'espace nous est donné par le déplacement des corps les uns par rapport aux autres et par leur interrelation, plus que par les images que la rétine enregistre ${ }^{90} »$ le mode déambulatoire constitue une forme de résolution (une démonstration) qui encourage un engagement du spectateur dans l'espace. Le principe déambulatoire n'est pas qu'une simple volonté de déplacement des spectateurs, il vise à mettre clairement en jeu le processus ${ }^{91}$, c'est-à-dire un acte dans son en-cours, un geste mouvant, changeant, se trans-formant qui m'importe autant que la production finale. Le déambulatoire est donc une expérience qui se constitue par une accumulation d'unités spatiotemporelles qui font vivre un temps cumulatif de temporalités. Dès lors, le spectateur devient complice d'un événement composé d'une multitude de modes de présence et doit, à chaque fois, choisir quelle place il doit/veut tenir dans chacune des propositions, qu'elles soient plus ou moins étranges ou stimulantes. II doit expérimenter le mouvement, l'hétérogénéité, et la simultanéité des signes et re-trouver,

\footnotetext{
${ }^{90}$ Josette Féral, op.cit. p. 134. Elle souligne que selon l'architecte autrichien F. Kiesler in " Debacle of the Modern Theatre ", The Little Review 11, Winter 1926: 67. "L'espace n'existe comme espace que pour la personne qui s'y déplace. Pour l'acteur, non pour le spectateur $\gg$.

${ }_{91}$ Le mot processus vient du latin pro (au sens de «vers l'avant ") et de cessus, cedere (aller, marcher) ce qui signifie donc aller vers l'avant, avancer. http:/fr.wikipedia.org/wiki/Processus (consulté le 01/09/2010)
} 
ré-inventer sa place. Le spectateur, ainsi amené à participer au déroulement de l'événement, se trouve conditionné par la spécificité du lieu (ou du dispositif). Il est placé en situation, « c'est lui qui tourne la tête pour percevoir ce qui l'entoure, c'est lui qui choisit son point de vue ou en change. La pluralité des espaces ainsi découpés dans le champ visuel relativise fortement l'homogénéité d'une vision de l'espace géométrique ${ }^{92} \gg .11$ est incité à prendre la responsabilité de ses actions ou de ses non-actions. Enfin, la dynamique déambulatoire fomente une activation polysensorielle qui avive les relations du spectateur à son être au monde. Que va-t-il ressortir de cette expérience? Au fond, la réponse m'importe peu, car l'intérêt résulte surtout de l'expérience qu'il va retirer de cette proposition et des sensations qui vont découler de sa subjectivité.

De plus, le concept de mise en espace me permet de réfléchir à l'agencement théâtral afin de mettre en place des conditions d'irruption du réel. Je pense, en effet, que la sensation d'être là se vit avec beaucoup plus d'acuité lorsque l'on est placé dans une situation où l'on doit effectuer des va-et-vient entre une perception de structure et le réel sensoriel qui nous entoure ${ }^{93}$. Cette porosité des frontières dérange apparemment un ordre

\footnotetext{
92 Anne Cauquelin, op.cit. p. 148. Elle mentionne aussi que « ce que l'in situ met en relief ce sont les conditions d'une mise situation. Le site in situ est situation et met en situation, c'est-à-dire en condition. L'œuvre est sa condition même. Événementiel, contingent, (...) il n'est en effet que le simple révélateur de ce qui este, d'un état de choses, de leurs relations entre elles, qu'il signale ». p. 152.

${ }^{93}$ Dans un travail antérieur, $j$ 'ai mis en espace Les mains bleues de Larry Tremblay dans un local décati qui avait pignon sur la rue principale du centre-ville de Chicoutimi et sur un stationnement intérieur. Javais alors éprouvé de vives sensations à faire des va-et-viententre le réel (extérieur) et ce qui se déroulait à l'intérieur. Les différents stimuli (sons, sensation de mouvements, lumière) provenant de part ế d'autre du local, enrichissaient la dramaturgie, alimentaient la proposition de jeu et avivaient ma sensation d'être là, en relation avec te monde qui m'entoure.
} 
donné puisque l'imprévisible s'immisce dans les structures de l'œuvre. De sorte que cet échange favorise une manière d'être là avec l'Autre au cœur du monde.

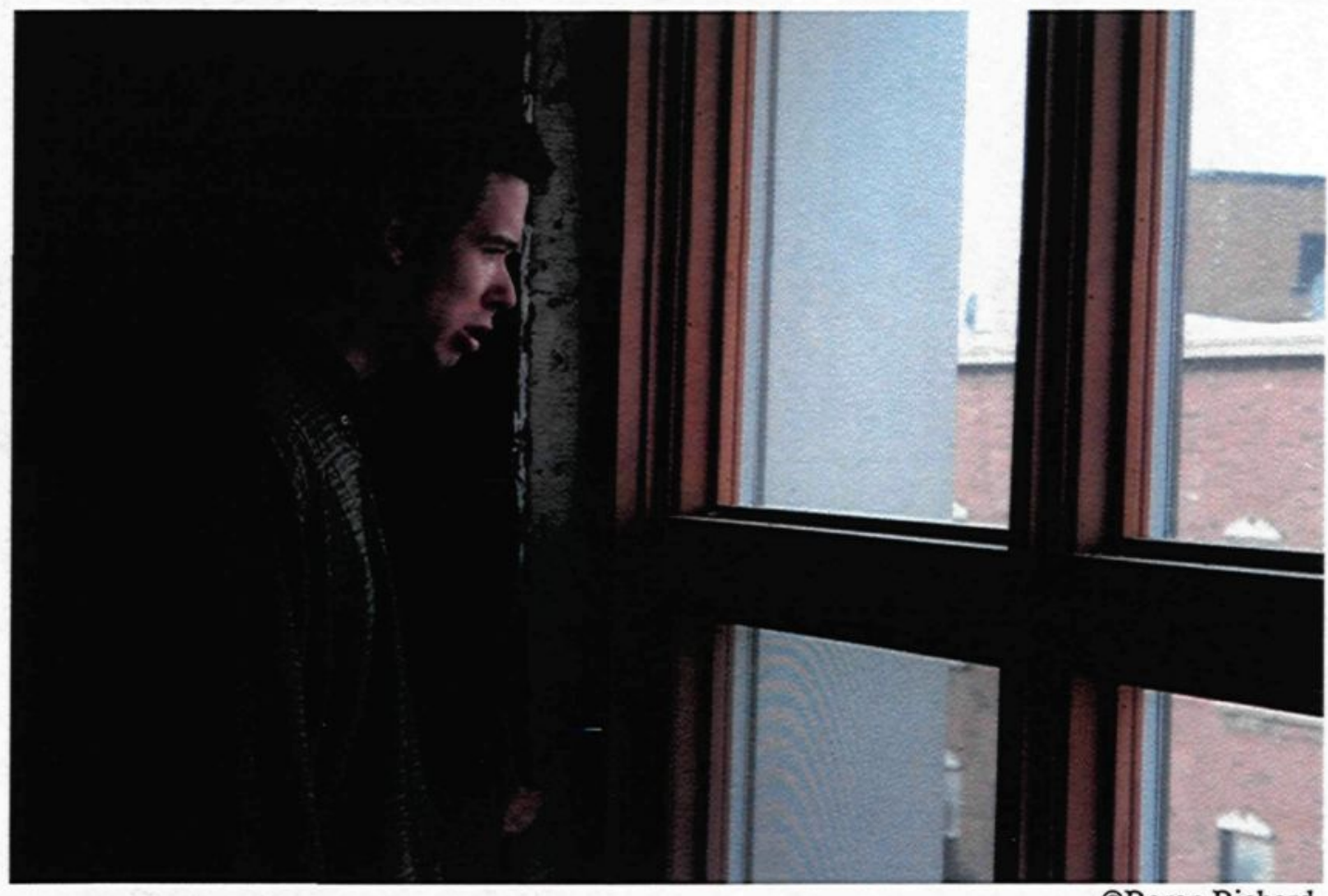

CBoran Richard

Figure 1. Jérémie (Jonathan Boies) des mains bleues à la frontière du réel. 


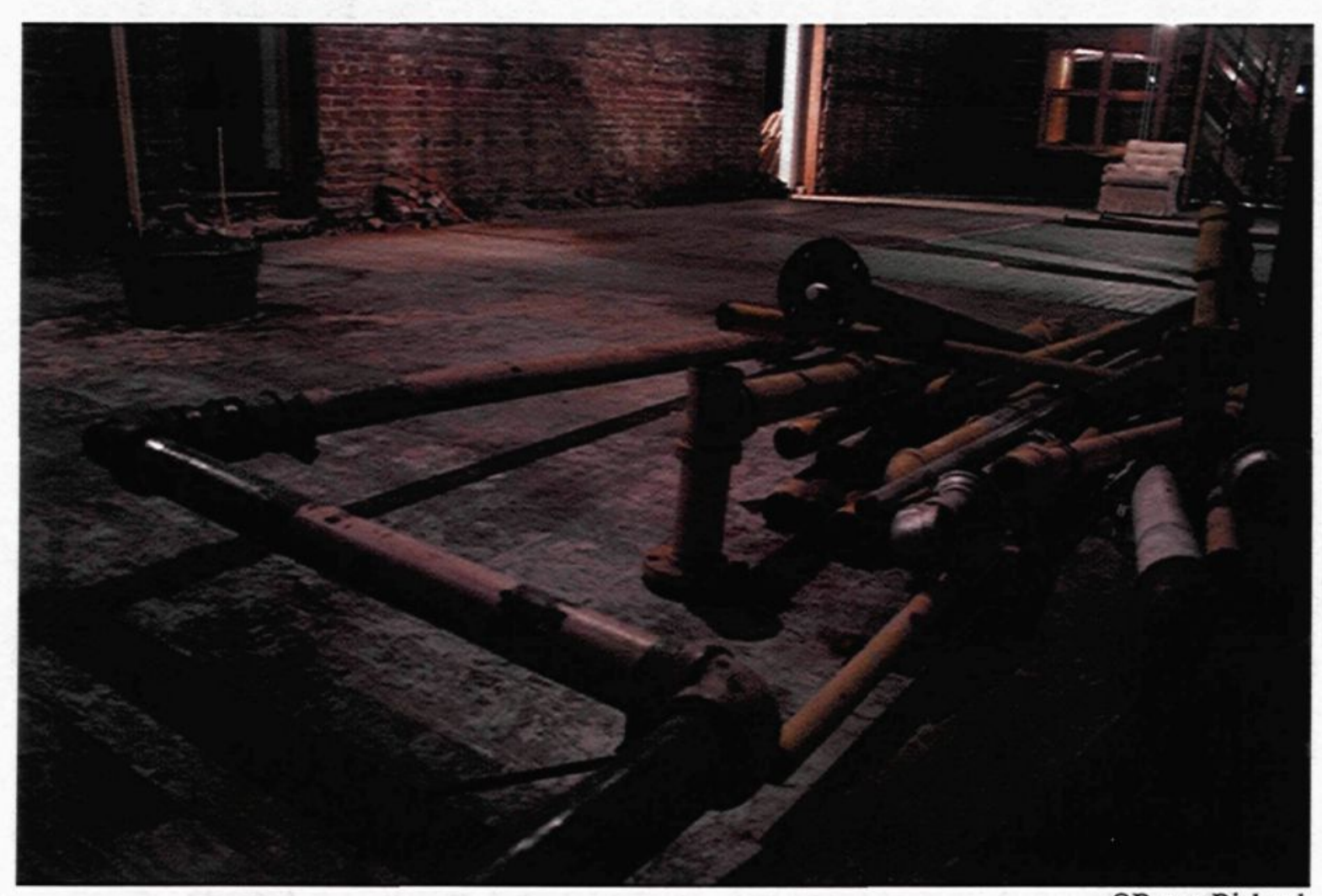

@Boran Richard

Figure 2. Vue partielle et latérale de l'espace des mains bleues. Un espace installatif composé à partir des matériaux trouvés sur place. On peut repérer la fenêtre tout au fond qui donne sur une rue du centre-ville de Chicoutimi et à l'opposé, (tout à côté, depuis le site du photographe), se trouvaient des portes métalliques qui s'ouvraient sur un stationnement intérieur plutôt achalandé et bruyant.

Avec ce projet, j'ai cherché à jouer avec les cadres et les modes de perception de l'univers spatial qui nous entourait, $\mathrm{j}$ 'ai pu brouiller la frontière entre la fiction et la réalité, déstabiliser les perceptions usuelles et réveiller notre contact avec le monde. À l'instar de cette création, cette manière d'investir le monde comme événement, comme expérience sensible d'inspiration phénoménologique suppose que chaque performance, même si le projet est présenté plusieurs fois, soit le lieu de l'éphémère et évolue, varie, selon les 
données du contexte. Elle se veut lieu du renouveau, de l'instant présent, du mouvement, un espace dialogique et critique par excellence qui nécessite, pour les acteurs et les coacteurs de cette situation, une manière d'être là et de jouer, présents à ce qui se vit ici et maintenant et ouverts à ce qui peut advenir.

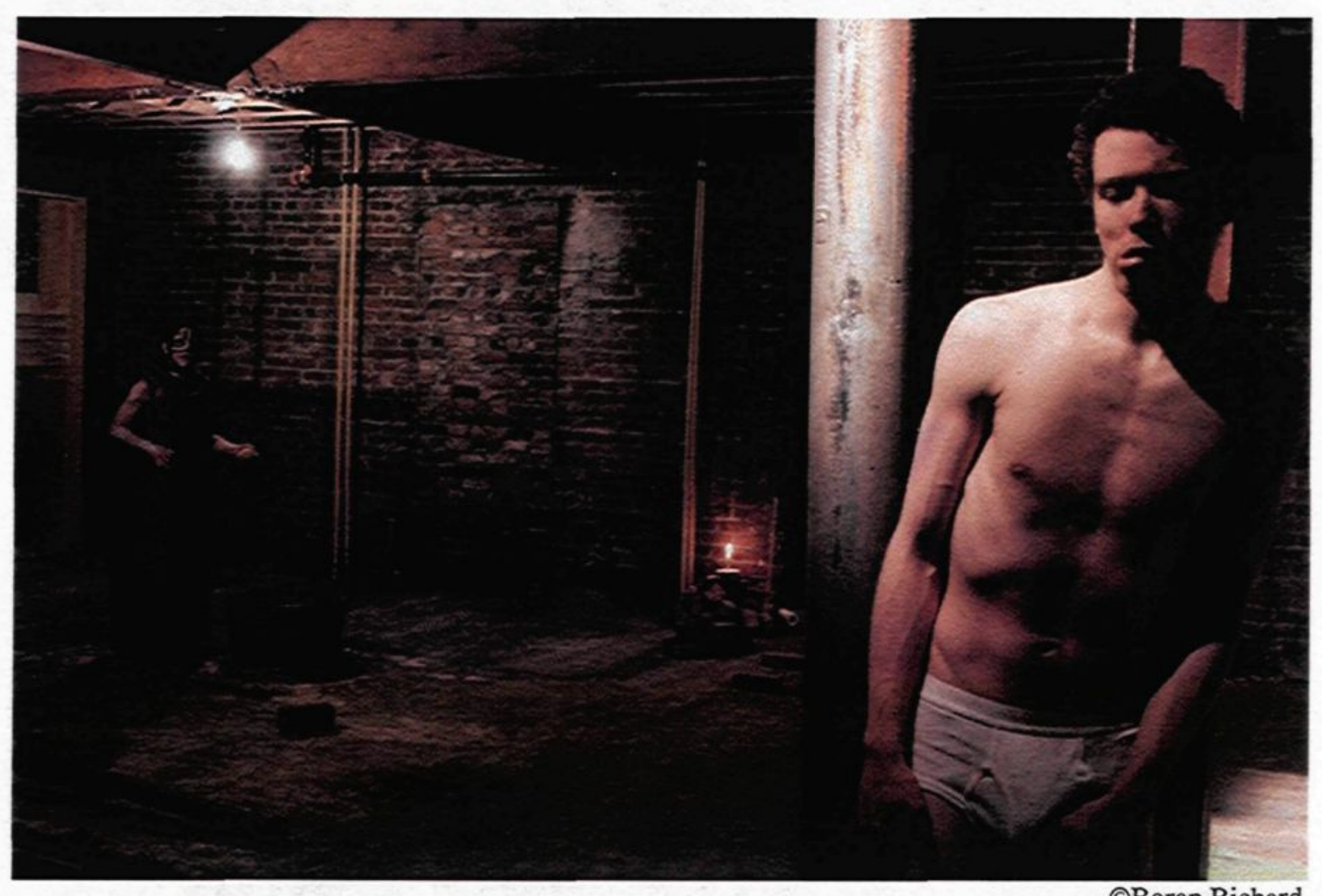

@Boran Richard

Figure 3. Les acteurs en situation de jeu dans l'espace des mains bleues. Guylaine Rivard (Princesse) et Jonathan Boies (Jérémie) avaient pour consigne d'accueillir les différentes perturbations provenant du réel, comme des occasions d'aviver leur « présence au moment présent », c'est-à-dire qu'ils devaient, par exemple, prendre le temps d'écouter le son d'un klaxon, des voix extérieures ou encore le vrombissement d'un moteur avant de poursuivre le récit. Cette indication eut un impact majeur sur le jeu des acteurs (intensifiant leur présence) et sur notre expérience de spectateur. 
Que ce soit sur ce projet de fin de baccalauréat, Les mains blenes, ou sur les autres que j'ai traversés, l'approche phénoménologique irrigue mon travail de recherche et d'expérimentations. La phénoménologie de la perception est un filon inouï pour développer ma recherche de matérialité et pour élaborer le concept de mise en espace. Ma pratique se déploie dans le désir de faire participer le spectateur à un événement auquel il n'assiste pas toujours frontalement, mais qui l'entoure et le saisit afin de lui faire ressentir la charge énergétique d'une œuvre poétique. Ainsi, dans l'ensemble de mes explorations, il m'apparaît important de conceptualiser l'espace et ses possibles, pour opérer un détournement du lieu (théâtral ou autre) afin de le concevoir comme le lieu du visible, de l'audible, du sensible, de l'imprévisible, de la fabrication et de la manifestation du sens. Mon objectif de recherche et création consiste essentiellement à découvrir comment le lieu théâtral peut être simplement un travail concret sur l'espace, le temps, la matière, la couleur, la corporalité, le geste, le mouvement, le rythme, le son, «la parole et le souffle qui crache la vie $e^{94} »$, de sorte que l'actualité de la présence physique des corps l'emporte sur le logos. Ainsi, en portant mon attention sur les potentiels artistiques de la décomposition de la perception, je peux explorer différents stimuli sensoriels qui sont de nature à faire vivre une expérience (somatique, kinesthésique, imaginaire) au spectateur. Cette recherche de seuils sensoriels liés à la perception et à notre ouverture au monde n'exclut pas une exacerbation violente des sens. J'invite alors le spectateur à vivre une expérience esthétique sensible, susceptible de l'interpeller dans la multiplicité de son être (pensée critique, perception, affect, corps, sensation et imagination).

\footnotetext{
${ }^{94}$ Antonin Artaud, op.cit. p. 703.
} 
Cette approche phénoménologique envers le spectateur concerne aussi ma demande auprès de l'acteur. Aussi, en ce qui a trait au jeu dramatique, je mets en place un protocole pratique de travail avec les acteurs, un entrainement spécifique, constitué de différents exercices pour le corps et la voix leur permettant de construire une concentration ouverte à l'intégralité de leur environnement et une conscience des caractéristiques phénoménologiques de la présence. Ce qui me permet d'aborder le jeu avec les acteurs dans le but, non pas de représenter une histoire ou un récit, mais bien de produire un événement. Je pense que le théâtre est le lieu où le texte se risque dans l'espace et qu'à cet égard il faut prendre en charge la parole d'un auteur dans le sens d'un déploiement, d'un geste, d'un mouvement, d'un rythme, d'une musicalité, voire d'une partition rythmique et musicale. Je cherche à diriger les acteurs afin qu'ils en viennent à considérer leur corps comme expression de la parole ${ }^{95}$; que cette parole soit conçue comme l'un des usages possibles de leur corps et qu'en ce sens, ils doivent travailler sur l'essence, le style articulaire et sonore des mots.

Mais que l'on en revienne si peu que ce soit aux sources respiratoires, plastiques, actives du langage, que l'on rattache les mots aux mouvements physiques qui leur ont donné naissance, et que le côté logique et discursif de la parole disparaisse sous son côté physique et affectif, c'est-à-dire que les mots $[. .$.$] soient entendus comme$ leur angle sonore, soient perçus comme des mouvements ${ }^{96}[\ldots]$.

Je m'engage done dans un travail d'exploration du corps, du geste, de la parole, de la voix, de la respiration et du rythme. Je pourrais dire qu'en continuité avec ma recherche

\footnotetext{
${ }^{95}$ Expression tirée d'un chapitre du livre de Merleau-Ponty, La phénoménologie de la perception, Gallimard, coll. « Tel ", Paris, 1945. Ce chapitre m"apparaît comme un véritable petit précis de prise en charge de la parole.

${ }^{96}$ Antonin Artaud, op.cit. p. 578.
} 
de matérialité concernant l'espace, c'est dans un rapport réel, tangible, de corps humains agissants et parlants, que réside mon approche. Mon travail avec les acteurs ne procède pas d'une application des règles traditionnelles du jeu qui visent la vraisemblance (analyse des motivations psychologiques des personnages, découpage du texte en saucisson d'intentions intelligentes et tutti quanti). Je m'intéresse à un autre type de travail d'acteur, au corps et au dire qui s'éprouve dans l'espace, dans le risque et le plaisir d'être là, de dire et de faire dans le présent, ici et maintenant. Une présence au présent où le corps est le centre de gravité, non pas comme porteur de sens, mais dans sa substance physique, son potentiel vocal et gestuel. Il ne formule pas un sens, mais articule une énergie; il ne représente pas une réalité, mais un agir dans le présent de la performance. À cet égard, les injonctions de Novarina dans sa Lettre aux acteurs sont inspirantes.

Des bouts de textes doivent être mordus, attaqués méchamment par les mangeuses (lèvres, dents); d'autres morceaux doivent être vite gobés, déglutis, engloutis, aspirés, avalés. [...] Beaucoup de texte doit être lancé d'un souffle, sans reprendre son souffle, en l'usant tout. Tout dépenser. Pas garder ses petites réserves, pas avoir peur de s'essouffler. Semble que c'est comme ça qu'on trouve le rythme, les différentes respirations, en se lançant en chute libre. [...] Faut pas faire les intelligents, mais mettre les ventres, les dents, les mâchoires au travai1 ${ }^{97}$.

Mon approche pratique est physique et concrète, elle relève de notre manière d'être au monde, d'exister dans le temps et dans l'espace. Elle appelle une phénoménologie de la voix mais aussi du geste. En orientant le travail sur la voix, le texte laisse apparaitre son origine; il devient un tissu pour matière sonore et spatiale qui dépasse la seule fonction de

\footnotetext{
${ }^{97}$ Valère Novarina, Pour Louis de Funès, précédé de Lettre aux acteurs, Arles, Actes Sud, 1986, p. 10-11.
} 
véhicule du sens ef de l'expression. On peut même dire que le travail sonore sur la voix crée l'espace et ouvre la voie vers une circulation plus libre des sens et de la sensation puisqu'il établit un rapport inédit au corps et engendre une perception synesthésique qui pénètre la chair du sensible.

[...] le mot [oralité], en référant à la voix humaine et à la bouche dont elle sort, évoque des faits d'une extrême complexité, engageant l'existence entière de l'émetteur de cette voix, son corps, sa psyché, sa personnalité sociale. Le terme oralité est aussi riche que la vie même; non moins qu'elle, polymorphe et ambigu. [..] Or, quoiqu'elle échappe à la vue, au toucher, au goût, rien n'est plus concret que notre voix. J'élève la mienne, et voici que se produit un événement : dans l'univers sonore, quelque chose nât, éphémère, mais dont la trace s'imprime sans autre médiation dans l'esprit et le cour, établissant un contact ineffable et intime entre celui qui la perçoit et moi de qui elle émane ${ }^{98}$.

Ainsi dans cette partie, j'ai tenté de ramener mon propos théorique sur le concept de mise en espace à une explication plus pratique. J'ai voulu montrer que cette écriture spatiale offre une possibilité concrète de collaboration avec d'autres disciplines qui multiplie le potentiel hétéromorphique de la création théâtrale. Puis, j'ai insisté sur ma stratégie spatiale pour inviter le spectateur à se déplacer non seulement dans sa perception, mais dans son implication physique au sein de l'événement. Il a ainsi le choix de vivre une expérience au lieu d'assister à une représentation théâtrale. Pour appuyer cette intention artistique, je me réfère à la dynamique phénoménologique. Elle me permet d'approfondir une recherche de matérialité envers le spectateur et tout autant auprès de l'acteur. Après

\footnotetext{
${ }^{98}$ Paul Zumthor, «Sonorité, oralité, vocalité » in Oralités - Polyphonix 16 « La pensée se fait dans la bouche », Québec, Les Éditions Intervention \& CRELIQ. 1992, p. 17-24.
} 
avoir décrit le travail de l'acteur qui contribue à la physicalité, voire la corporéité, de mon approche spatiale, je vais donc exposer le projet artistique, Filles de guerres lasses de Dominick Parenteau-Lebeuf, qui devra porter l'ensemble de ces hypothèses de recherche. 


\title{
CHAPITRE IV
}

\section{LA CREATION DE FILLES DE GUERRES LASSES}

DE DOMINICK PARENTEAU-LEBEUF

\author{
UN PARCOURS DEAAMBULATOIRE
}


Sans un élément de cruauté à la base de tout spectacle, le théâtre n'est pas possible. Dans l'état de dégénérescence où nous sommes, c'est par la peau qu'on fera rentrer la métaphysique dans les esprits ${ }^{99}$.

Mon travail de recherche suppose l'emploi d'une matière textuelle au potentiel protéiforme afin d'expérimenter l'oralité dans sa dimension performative. En ce sens, les écritures théâtrales contemporaines sont un formidable terreau pour développer une pratique interdisciplinaire et hétéromorphique qui se déploie dans une dynamique spatiale. À cette fin, Filles de guerres lasses de Dominick Parenteau-Lebeuf (DPL) est une ceuvre intéressante pour explorer concrètement les hypothèses que j'avance dans cet essai. Les textes qui composent l'opus Filles de guerres lasses ont été écrits entre 1996 et 2002 dans le cadre de différents projets littéraires et théâtraux et ont été réunis en 2003 sous leur titre actuel. La pièce comprend donc quatre courts textes, autonomes en eux-mêmes, et intitulés Icône. La description qu'elle en fait foumit un indice du ton employé : « dans l'Église de rite chrétien oriental, peinture religieuse sur bois. Ici, dans le monde occidental, fille peinturée dans un coin jusqu'à nowvel ordre ${ }^{100} \ggg$. DPL note aussi que pour le découpage de la parole dans les trois premiers textes, la distribution doit se faire par le metteur en scène. Elle préfère, écrit-elle, « lui laisser le soin de créer sa propre polyphonie selon son oreille et sa perception ${ }^{101} \%$.

\footnotetext{
${ }^{99}$ Antonin Artaud, op.cit. p. 565.

${ }^{100}$ Dominick Parenteau-Lebeuf, Filles de guerres lasses, Morlanwelz (Belgique), Lansman, coll. « Nocturnes Thêâtres »,2005, p. 1.

${ }^{101}$ Dominick Parenteau-Lebeuf, op.cit. p. 4.
} 
Son travail d'écriture est manifestement marqué d'une pulsion rhapsodique ${ }^{102}$. Elle développe un certain nombre de procédés qui contribuent à émanciper le dialogue de théâtre, à le rendre multidimensionnel et polyphonique. Ses personnages se déplacent vers la Figure ${ }^{103}$ et ont tendance « $\dot{a}$ devenir témoin un personnage témoin de lui-même et de l'action dans lequel il esi pris ${ }^{104}$ ". Une multitude de voix s'additionnent, se fragmentent et se délocalisent du personnage traditionnel complexifiant ainsi l'interaction avec le spectateur. Loin d'être toujours convergentes, ces voix se juxtaposent les unes aux autres, entrent en concurrence, créent des contrastes marqués, nuancent le propos ou encore entraînent des digressions imprévisibles ou des effets de choralité. Sans contredit, DPL est un auteur-rhapsode qui «fait dialoguer les monologues ${ }^{105} »$. Ces discours enrichissent la totalité en démultipliant les points de vue, les angles d'attaque et les tons. Dès lors, ces voix rythment et marquent de leur empreinte la composition d'ensemble et engagent un dialogisme hétéromorphique.

Filles de guerres lasses est donc une structure à plusieurs dimensions qui forme un ensemble qui se décline dans une multiplicité de dispositifs où chaque texte suppose sa

\footnotetext{
102Jean-Pierre Sarrazac, op.cit. p. 13-16. Il analyse ainsi la force à l'œuvre dans les nouvelles formes de dialogue qui se multiplient dans le théâtre contemporain. On y relève la présence d'une pluralité de modes poétiques et de voix hétérogènes qui s'entrelacentet entretiennent entre eux des rapports dialogiques.

103 Gilles Deleuze dans Francis Bacon Logique de la sensation, Paris, Éditions du Seuil, coll. « L'ordre philosophique », 2002, p. 42-43. Il indique que «la Figure affirme son intention de rompre avec le figuratif». La Figure est donc, d'une certaine manière, la matérialisation de la Sensation et s'oppose à la figuration et au représenté. Je transpose cette analyse en peinture au jeu théâtral afin de m'aider à déconstruire la notion de personnage psychologique et à re-figurer l'incarnation au théâtre.

${ }^{104}$ Sarrazac, op.cit. p. 14

105 Ibid., p. 16.
} 
propre polyphonie composée de solos, de duos, de trios et de chœurs. Ainsi, à la manière d'une courtepointe, l'opus est composé de pièces singulières, hétérogènes qui proposent un alliage alimentant l'altérité et la différence au sein d'un ensemble.

L'hétérogénéité est dans ce cas étroitement associé à l'idée de polyphonie, à ceci près qu'elle n'est pas seulement la trace d'une multiplicité des voix du dialogue mais surtout de leurs différences, de leur diversité fondamentale, qui permet un véritable dialogisme. Pour qu'il y ait dialogue au sens fort du terme et non simplement un monologue à plusieurs voix, il faut en effet une confrontation de singularités; or c'est justement ce choc des altérités qu'exhibe l'hétérogénéité ${ }^{106}[\ldots]$.

En outre, Dominick Parenteau-Lebeuf (DPL) nous invite explicitement à nous emparer de son texte et surtout, de sa parole polyphonique originale. J'ajoute donc ma voix à cette jeune parole féministe, poétique et drôle pour éprouver le concept de mise en espace plusieurs fois, plutôt qu'une! J'apprécie particulièrement le ludisme de sa proposition et souhaite que cet esprit habite le processus dans lequel je convie les acteurs et les spectateurs. Ces quatre courts textes abordent avec vivacité, légèreté et dérision des enjeux séculaires qui me touchent intimement. Et puis, au-delà des enjeux, son écriture est dynamisée par des effets de choralité qui font écho à mes préoccupations philosophiques et sociopolitiques. À la faveur de tous les récits qui sont ponctués par l'intervention de chœurs et d'une énonciation fragmentée, je peux explorer de nouvelles manières de partager une parole, tout en mettant en jeu quelques utopies, concernant notamment la question communautaire et le vivre-ensemble contemporain. L'événement déambulatoire Filles de

\footnotetext{
${ }^{106}$ Florence Baillet, «L'hétérogénéité » in Nowveaux territoires du dialogue, sous la dir. de Jean-Pierre Ryngaert, Arles, Actes Sud-Papiers/CNSAD, coll. «Apprendre », 2005, p. 28-29.
} 
guerres lasses semble à plusieurs égards l'allégorie parfaite de la trajectoire conceptuelle et esthétique développée dans ce mémoire.

Je souhaite faire un usage situationniste du milieu géographique de la présentation de Filles de guerres lasses, opérer des détournements afin de «transcender notre vision stéréotypée, nos sentiments conventionnels et nos coutumes, nos modes de jugement ${ }^{107}$ 》 et réactiver notre rapport au réel. Filles de guerres lasses me donne l'occasion de mettre en espace différentes figures de la femme pour questionner les représentations séculaires qui s'articulent généralement à partir de ces deux pôles: de l'idéalisation absolue à la diabolisation radicale.

Les spectateurs seront conviés à se vêtir en conséquence de la température et à apporter des lampes de poche. L'accueil se fera au Pavillon des arts par une majorette vêtue d'un uniforme militaire fantaisiste composé notamment d'instruments de musique (trompette, tambour, mélodica) et de bottes tambourinantes. Cette femme-orchestre distribuera des lampes de poche à ceux qui n'en ont pas et mènera les premiers temps de ce parcours déambulatoire. Le premier site choisi est tout près, derrière le Pavillon sportif de l'UQAC, à l'orée du boisé Val-Lombrette. C'est un lieu très accessible, adjacent au stationnement. Pour y accéder, on peut faire une petite ballade d'une quinzaine de minutes dans les sentiers dudit boisé (et profiter pleinement des couleurs, des odeurs et de la psychogéographie du lieu) ou y accéder directement par le stationnement.

107 Jerzy Grotowski, Vers un théâtre pauvre, Lausanne, L'Age dHomme, 1971, p. 215. 
Dans le premier temps du parcours, et si les conditions météorologiques le permettent, les spectateurs déambuleront dans le boisé de Val-Lombrette avant d'être conduits au site de la présentation de l'icône 1 : Vive la Canadienne ! Différents éléments insolites parsèmeront le terrain du réel, des in situ sonores et/ou visuels, qui seront plus ou moins apparents et devront être repérés par le spectateur (grâce à sa lampe de poche) puisqu'aucun éclairage spécifique ne sera mis en place. Je souhaite ainsi, dès les premiers moments de cette dérive et de ce pro-cessus, aviver la curiosité du spectateur, introduire un rapport ludique et sensoriel à l'environnement et susciter sa participation et son implication dans ce début d'événement. Les idées qui seront développées dans ces in situ sont des variations sur le thème de la femme (qu'est-ce qu'une icône féminine au XXIe siècle et surtout comment se présente-elle - se déplace-t-elle - lorsque c'est une femme qui est maître de sa re-présentation?) 


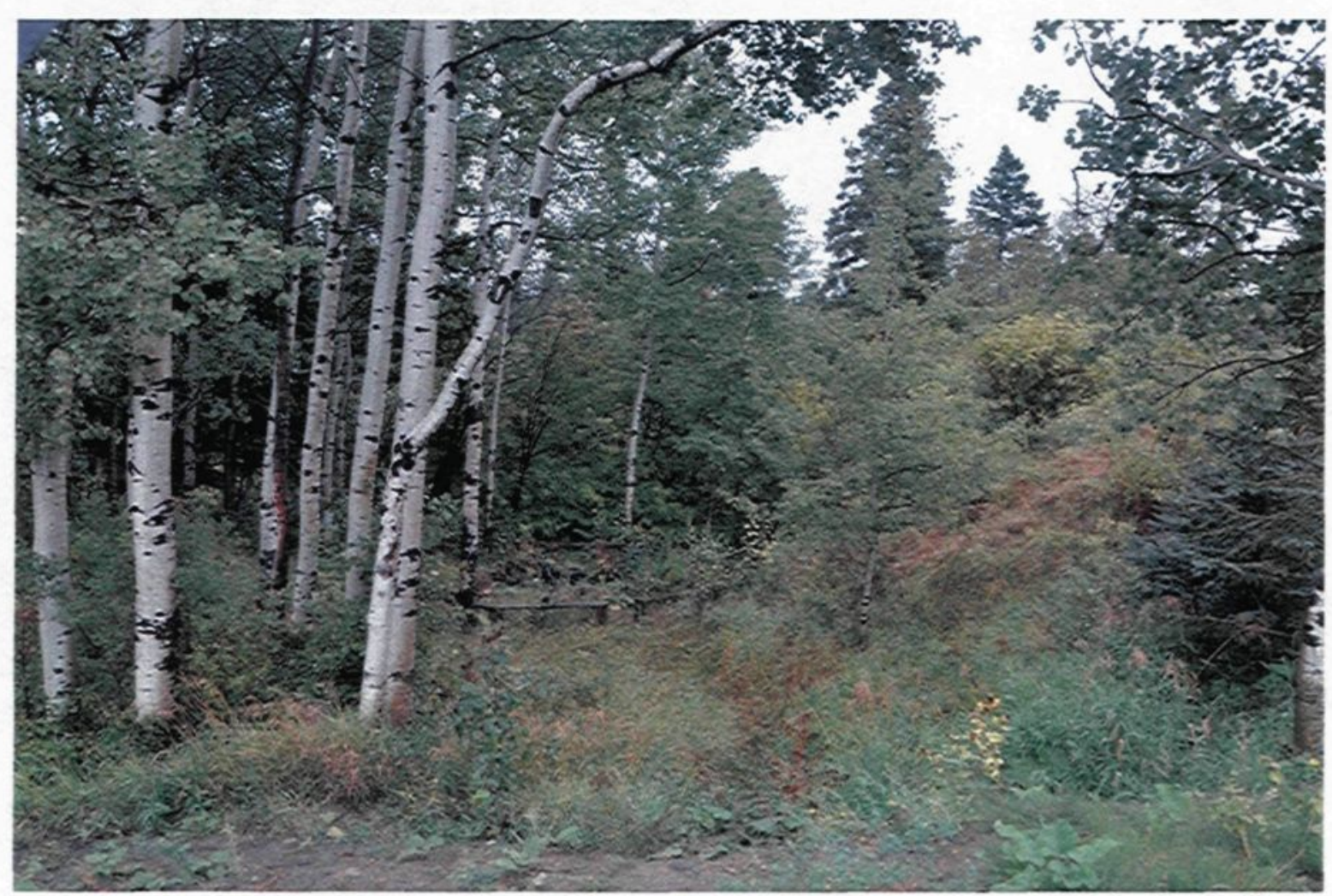

()Marie-Claude Simard

Figure 4. Espace vide pour l'Icône 1: Vive la Canadienne ! - Fillette, Marie-Paule Marsot rêvait d'être majorette. De brandir un bâton au son d'une fanfare, les cuisses au vent. Mais fille de féministe, elle a dû passer sa passion de la parade autrement. Cette nuit, alors que dans la forêt laurentienne la chanson Vive la Canadienne! retentit, les cuisses ouvertes, elle se souvient ${ }^{108}$.

Ainsi, après avoir marché, le spectateur parviendra dans un lieu constitué de longs bancs de bois construits de façon à former un grand cercle libérant un espace central appréciable. L'ensemble est ceinturé d'arbres et de pentes donnant l'impression que nous sommes au cœur de la forêt dans un endroit plutôt isolé. L'espace central du cercle est suffisamment grand pour y allumer un petit feu de camp. Les spectateurs seront assis sur

${ }^{108}$ Dominick Parenteau-Lebeuf, op.cit. Quatrième de couverture. 
ces bancs, munis de leurs lampes de poche, attendant que le "spectacle" commence. Aucune lampe (hormis le feu de camp) n'éclairera le site. C'est le spectateur qui collaborera à l'éclairage de la performance en déterminant les angles et les points de vue qu'il voudra bien mettre en lumière. Puisque le récit traite de façon fragmentée et décalée de l'initiation (un viol) d'une jeune femme, membre de l'armée canadienne, je commencerai cette mise en espace par un viol symbolique des spectateurs. Les acteurs (en l'occurrence les douze soldats qui forment le chcur) seront cachés dans le bois entourant ce cercle. Ils auront de petits émetteurs portatifs (des lecteurs mp3 avec préamplificateurs) qui émettront des sons préenregistrés de diverses natures (grondements, sifflements, ronflements, stridences, bruits de percussion, cris d'animaux). Au début, ils feront entendre leur son singulier de façon intermittente, puis ces sons finiront par composer un ensemble, le volume sonore augmentera jusqu'à ce qu'ils apparaissent pour prendre les spectateurs par la périphérie, entourant complètement le centre qu'ils occupent. Ce n'est qu'à la suite de cette introduction, que le récit débutera. La parole sera principalement partagée entre la figure de la fille et de la mère et sera ponctuée par les interventions du père, du responsable d'une commission d'enquête, d'une voix des renseignements, de la sœur, et du chœur de soldats. Bien que le sujet soit dramatique, il apparaît décalé par cet effet d'ensemble choral et hétérogène. 


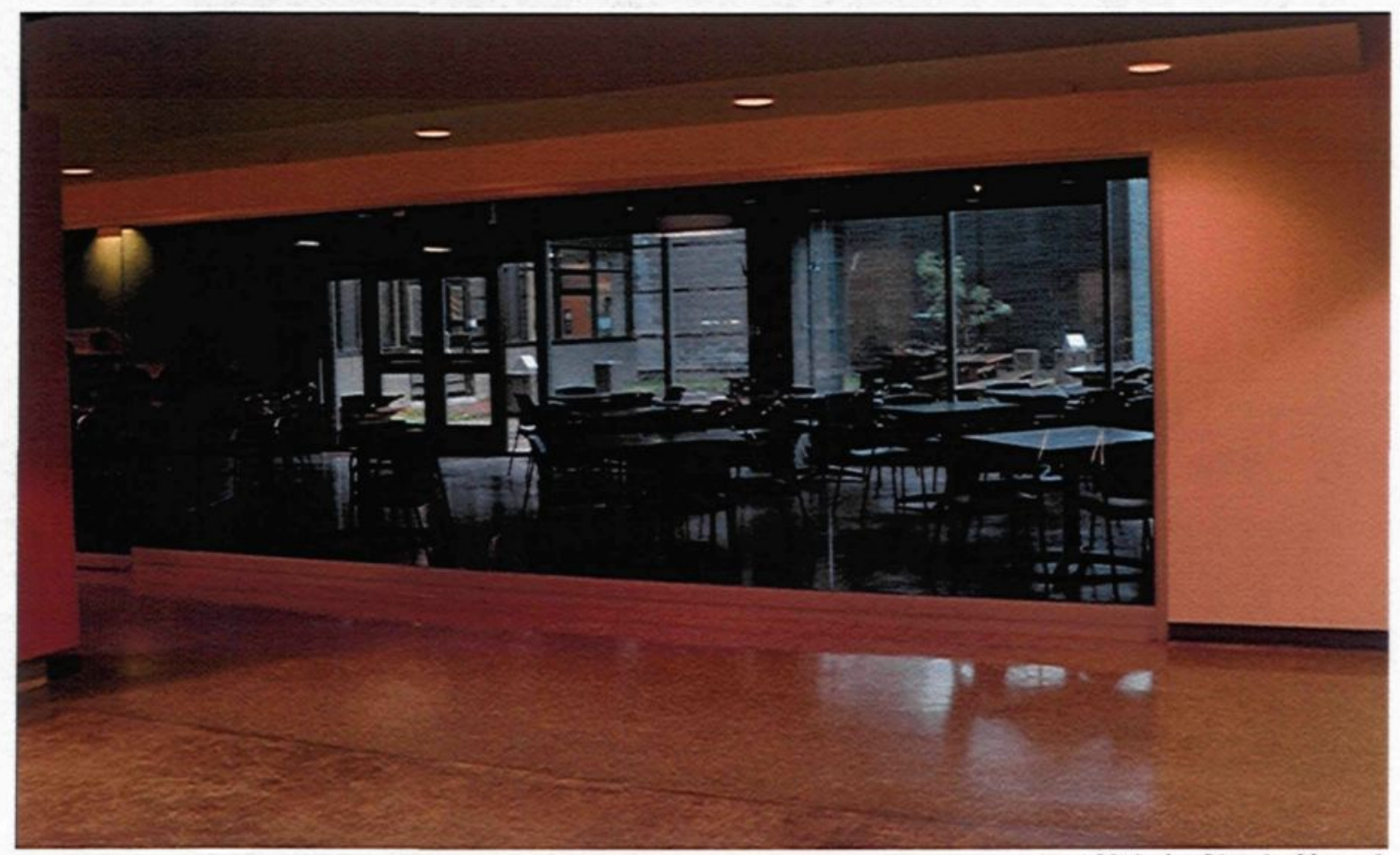

OMarie-Claude Simard

Figure 5. Espace vide pour l'Icône 2 : Vices cachés - Un rat sur un plancher de cuisine. Énorme. Menaçant. À quatre pattes sur la table, Maribel se demande comment ce monstre a pu pénétrer dans son appartement rutilant. La présence animale féconde ses pensées et ses entrailles. Comment l'expulser, à présent ? Si le corps féminin est une maison, alors la femme a ses vices cachés ${ }^{109}$.

Ce texte sera mis en espace dans cette petite pièce vitrée attenante à la cafétéria du centre social de l'UQAC que l'on nomme «l'aquarium », le P0-7000. Je compte d'abord réduire cet espace avec des cimaises recouvertes d'un matériau qui imite la céramique blanche et qui donneront l'indice de nouveaux murs afin de donner l'impression d'un grand cube. Le sol sera recouvert partiellement, et de façon déconstruite, de céramique blanche afin de conférer à l'espace un aspect clinique. Au centre de ce carré, une table de stainless

${ }^{109}$ Ibidem 
steel éclairée par une très forte lampe et une actrice montée sur cette table, tétanisée par la présence d'un (vrai) gros rat gris ế de petites souris. Le corps de cette femme est placé en observation sous ladite lampe et fait image. Deux autres actrices se joindront à elle afin de constituer un triplé pour fragmenter la parole de Maribel. Tout le reste de l'espace sera à vue (notamment l'acteur qui porte la parole du chum et la conceptrice sonore). Des présences qui seront à la fois visibles et discrètes. Les spectateurs seront postés à l'extérieur de ce gros cube, de chaque côté des baies vitrées. Il y aura donc une partie des spectateurs qui seront debout dans la petite cour extérieure du Pavillon des arts et l'autre partie se tiendra dans la cafétéria. D'un côté, il y aura donc cet espace clos, vitré, et de l'autre, deux espaces ouverts sur le monde, avec vue latérale sur cet espace vitré. Un dispositif où les actrices nous donneront la sensation d'être véritablement des objets de regard, sorte d'animal de laboratoire que l'on pourra observer depuis le confort d'une paroi vitrée. Toutefois, cette transparence s'avérera troublante puisque le regardant sera aussi regardé, mis en abîme, et potentiellement observé et fixé à son insu. Il sera pris dans un réseau, un chassé-croisé iconique qui se saisira de lui comme d'une figure parmi les figures, debout, en situation d'interface avec le monde, dans un rapport de proximité avec les autres. En outre, je souhaite présenter aux spectateurs une simultanéité de signes déhiérarchisés (le texte, les éléments sonores, visuels, gestuels, architecturaux seront concurrents). Le spectateur devra faire des choix et construire sa propre narration en négociant (le deul de) la cohésion de l'ensemble. Considérant que des microphones seront nécessaires pour faire entendre le récit de cette femme, des haut-parleurs seront disposés de part ế d'autre du cube, permettant ainsi de spatialiser le son en direct (une combinaison de sons produits en 
direct, de sons préenregistrés nous permettrons d'entendre le rat, les autres protagonistes du récit et différents bruits qui révèlent le réel de cet espace). Afin de manipuler et structurer délibérément l'espace sonore de cette icône, le son sera mixé en direct. Je souhaite perturber la perception en créant toutes sortes d'ambiguités et en ne donnant pas nécessairement à entendre la même chose de part et d'autre du cube. On pourra, par exemple, masquer le discours de Maribel par des bruits qui proviendraient de la cuisine, des toilettes, ou de la cour extérieure; faire entendre le rat en majeur et Maribel en mineur, etc. Quant au chcur de femmes, il se trouvera dispersé à travers les spectateurs de chaque côté de la paroi vitrée. Vêtues de robes noires, maquillées de faux-cils et munies de long plumeau blanc, ces femmes auront une présence ambigủe à travers les spectateurs. Elles seront affairées à faire du ménage et pourront répéter certains passages du texte entendus de façon chorale ou individuelle. 


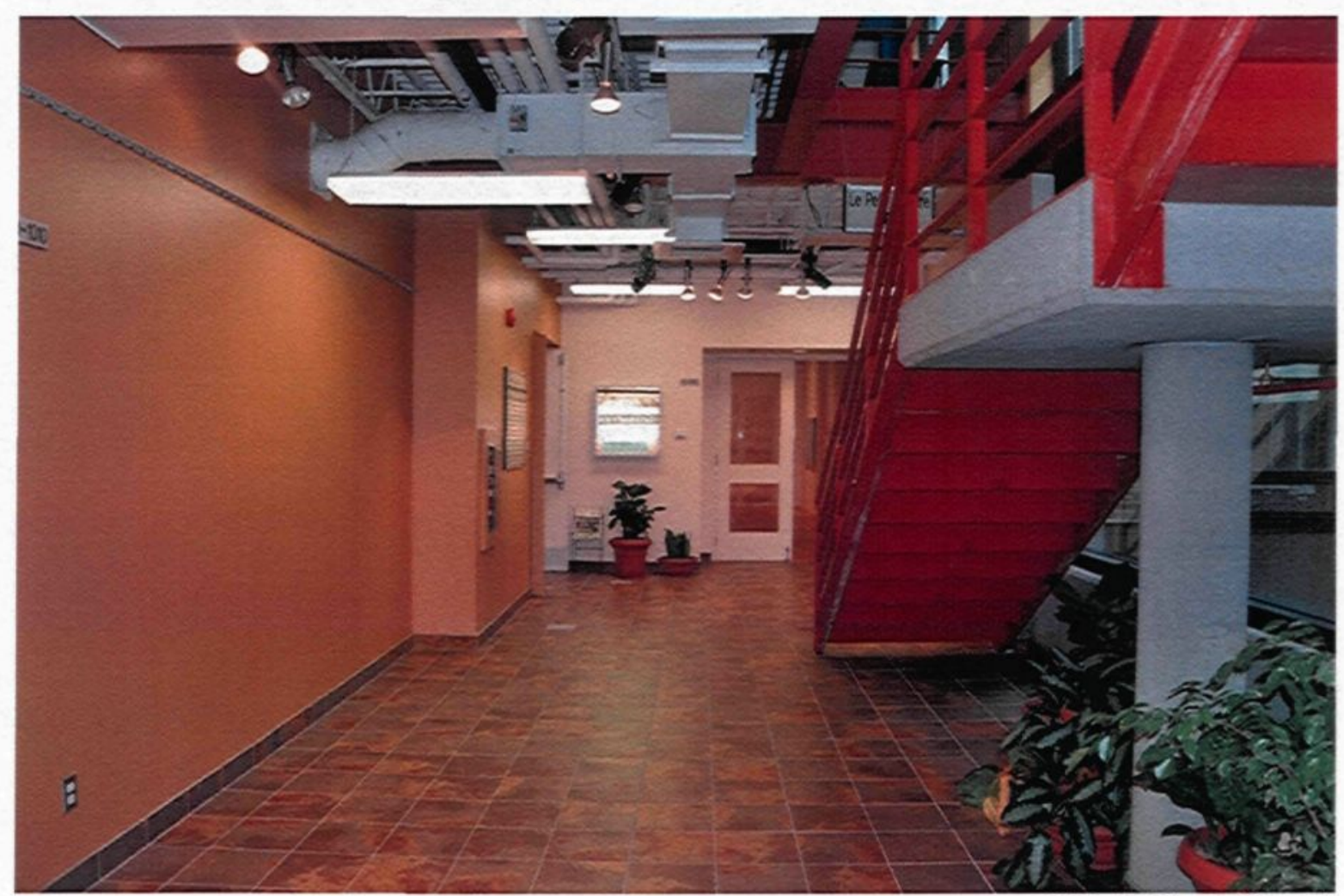

@Marie-Claude Simard

Figure 6. Espace vide pour l'Icône $\mathbf{3}$ : Nacre C - La poétesse Marie-Laurence Imbeau devient la muse Ellifal Sellif-Selertand à la suite de sa rencontre avec le jeune peintre branché Érod Rineva. Mettant sa poésie en jachère, elle pose pour lui. Commence alors la lente mutation de son épiderme en une somptueuse maladie de la peau : le nacre C. Miroir, $\hat{o}$ mon miroir, y a-t-il encore quelqu'un derrière cette beaute $e^{110}$.

L'étape suivante se tiendra dans le hall du Pavillon des arts. L'espace sera transformé en un lieu hybride entre le bar, la galerie d'art et l'atelier d'artiste. En entrant dans ce dispositif, les spectateurs pourront se procurer des consommations au bar. Étant donné que je tiens à réintroduire une corporéité à l'écoute de sa dimension proprioceptive, je solliciterai non seulement le regard, mais aussi toutes les autres facultés sensorielles du

${ }^{110}$ Ibidem 
spectateur (sensation de proximité des autres spectateurs et des acteurs, chaleur et effets de saturation des éclairages, empathie kinesthésique, etc.). Tout en demeurant réaliste sur ce que je peux faire pour métamorphoser l'espace du hall, je peindrai vraisemblablement plusieurs murs rouges et installerai un mur de miroir. Ce grand miroir aura une fonction transformatrice de l'espace habituel mais aussi un effet paradoxal sur les spectateurs qui pourront se voir dans le miroir et constater qu'ils font partie de l'image, ou encore (sans se voir), voir le miroir qui reflète le contexte où ils sont. L'éclairage, composé de nombreux spots, sera saturé de rouge. L'espace deviendra ainsi une scène où tous pourront être sous les feux des projecteurs. Des toiles composées de figures féminines et de parties du corps seront accrochées et décrochées pendant la performance. Je souhaite inviter le spectateur dans l'image afin qu'il se sente enveloppé et sillonnélll par l'action. Le caractère potentiellement explosif de l'atmosphère et de la dynamique spatiale s'avivera par les étranges déplacements que l'on fera faire à une actrice qui se chosifie parmi les spectateurs. De manière chorégraphique, je souhaite accroître la corporéité des acteurs par un répertoire de gestes inusités qui révèlent des possibilités inattendues du corps. Je souhaite développer ce langage corporel dans un esprit paradoxal, lenteur des gestes, réduction minimale des mouvements, jusqu'à statufier l'actrice de façon insistante, voire violente. Elle sera alors déplacée et placée à travers les spectateurs comme un objet. Je pense que ces déplacements et la proximité (parfois gênante) des acteurs permettront au spectateur d'appréhender l'espace qui l'entoure comme un lieu mouvant, un champ énergétique générateur d'intensité et de forces.

11 Expression employée par Artaud dans Le Théâtre et son double, op. cit., p.563. 


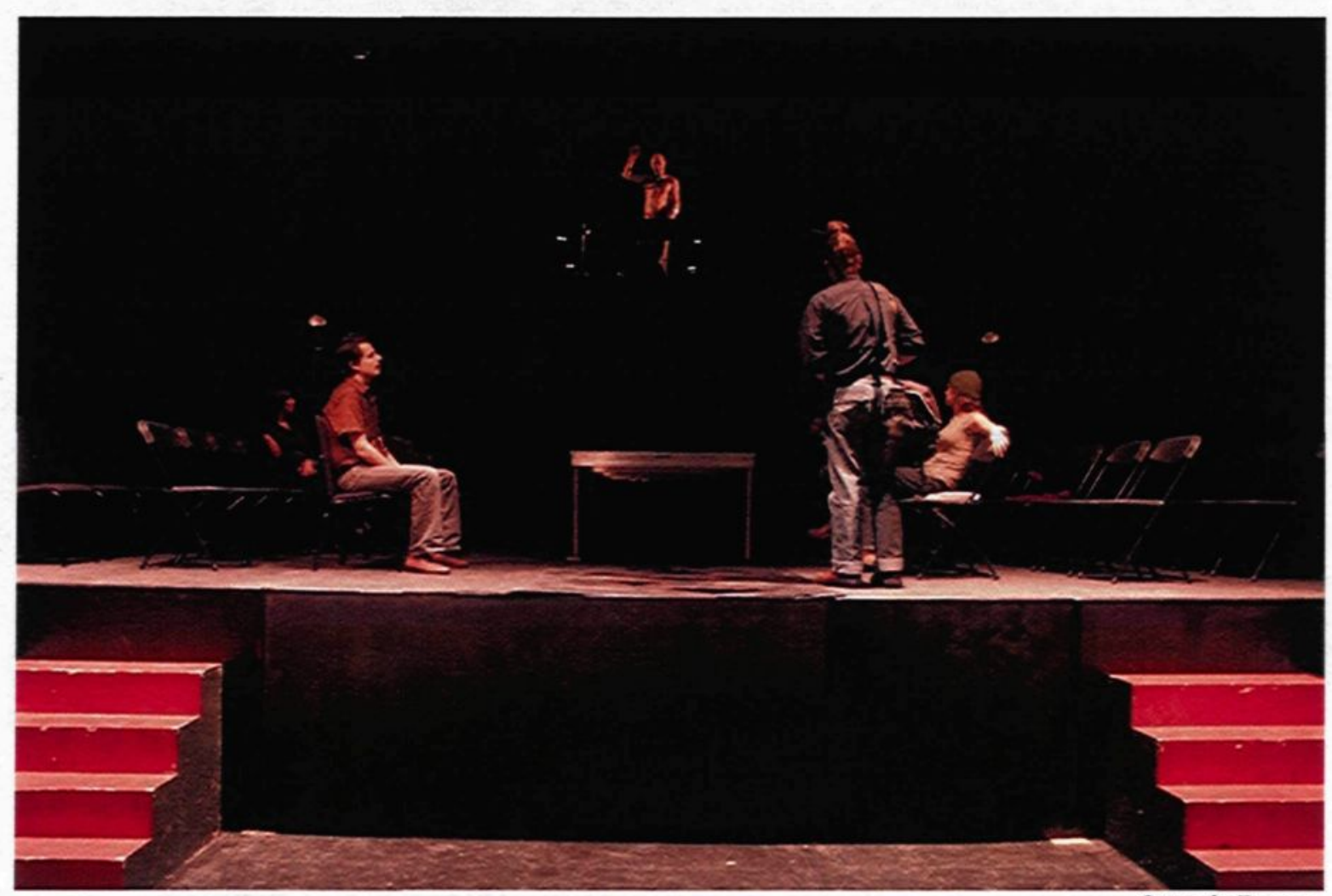

Figure 7. Dispositif "boûte-bunker" de l'Icône 4 : Catwalk, sept voix pour sept voiles Nous sommes en Galilée, territoire occupé. Salomé, une jeune mannequin palestinienne, s'effondre sur le podium alors qu'elle défile, vêtue de la dernière création du styliste JeanBaptiste Bensimon: une robe à sept voiles faisant d'elle le symbole de la réconciliation. Qui gagnera lorsqu'elle se relèvera? L'art ou la guerre ?'12

Voici maintenant deux photos du dispositif, tel que conçu et présenté dans le cadre de mes activités de recherche à la maîtrise. Il prendra essentiellement la même forme. Pour cette icône, je construirai donc ce dispositif dans le Studio théâtre de l'UQAC. Une installation spatiale qui inclu les spectateurs dans l'aire de jeu. Un espace-volume qui place les spectateurs dans une structure de perception verticale composée de trois étages superposés qui permet au regard de ne plus balayer le champ visuel de manière horizontale,

\footnotetext{
${ }^{112}$ Ibidem
} 
mais de procéder dans un axe vertical. La prégnance du regard dans la saisie sensorielle est alors court-circuitée puisqu'il y a très peu à voir, obligeant alors le spectateur à s'engager dans une perception plus auditive et kinesthésique. Ce dispositif prendra la forme d'une grande boite-bunker noire qui fera presque tout l'espace de la salle (plus ou moins 12 X 14 mètres et 1,50 mètre de hauteur) avec en son centre une fente, une fêlure qui partagera l'espace en deux et au-dessus de laquelle il y aura une passerelle (un catwalk). Les spectateurs seront assis de part et d'autre de la felure-passerelle sur le toit de ladite boittebunker. Ils comprendront qu'ils sont aussi coacteurs puisqu'ils apprendront au cours du récit qu'ils font figure soit de Palestiniens, soit de Juifs. En dessous (dans le bunker) se trouvera un chœur de femmes, que nous pourrons entrevoir de façon fugace par la felure. C'est essentiellement par la médiation de leurs voix amplifiées que nous les sentirons puisque leur parole proviendra du sous-sol des spectateurs. J'aurai donc recours à des micros pour les sonoriser, mais aussi pour mettre en espace leurs voix en manipulant différents paramètres du son afin de modifier et spatialiser leurs voix. De puissantes colonnes de son seront placées dans cet espace de façon à ce que l'on sente vibrer et passer des flux sur le sol des spectateurs. Quant aux acteurs qui assument les différentes paroles des six personnages, ils seront pour la plupart intégrés de façon complètement anonyme dans le corps spectatorial et se lèveront pour prendre parole le moment venu. Il n'y aura donc pas à proprement parler d'entrées et de sorties, hormis l'actrice qui paradera en robe de mariée, et qui tombera au sol dès son entrée. Dès lors, les différents personnages commenteront cette chute à tour de rôle. Puis, tout en haut, dans une fenêtre, trônera un DJ qui nous fera jouer des musiques électroniques et qui commentera cet étrange défilé. La 
robe sera spectaculaire: transparente (tout en permettant de camoufler une arme automatique sur une cuisse), conjuguée à un voile de type niqab ou burqa, pour donner une allure spectrale et paradoxale à ce vêtement.

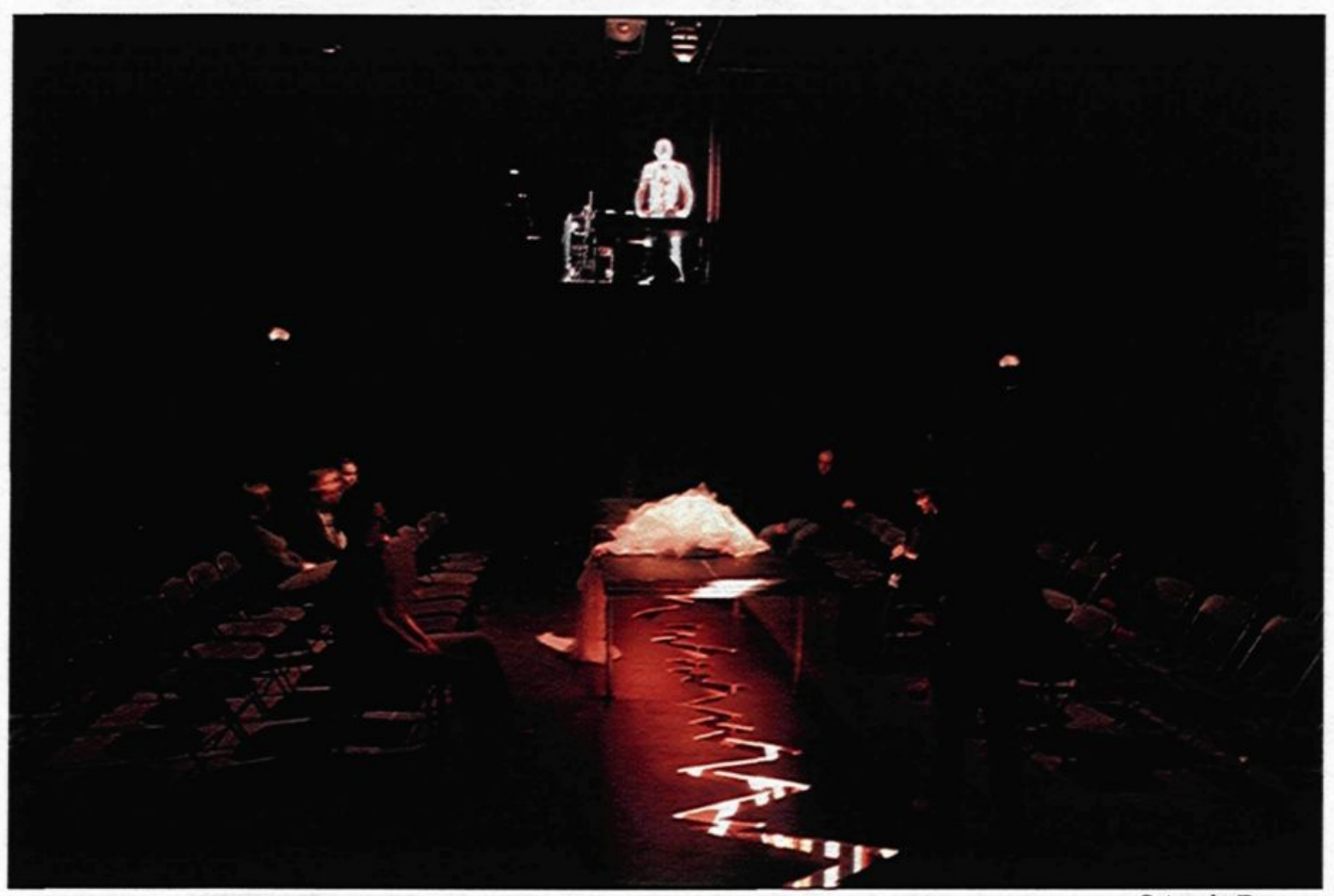

C)Annie Perron

Figure 8. Plan mitoyen du dispositif de l'Icône 4 : Catwalk, sept voix pour sept voiles 
L'ensemble de cette mise en cuvre rassemblera une quarantaine de personnes sur quatre espaces différents. Il va s'en dire que ce projet repose sur des pratiques collaboratives qui enrichissent (et déplacent) constamment la proposition de création. En considérant que l'art collaboratif actuel, qui a pour principe la création collective, résulte d'un ensemble d'actions indépendantes mises en lien par une aventure de création, on peut estimer que ce procédé rejoint la notion d'intermédialité sans rejeter les bases du théâtre. Cet événement théâtral cherchera à transformer le théâtre par lui-même tout en expérimentant des cocréations avec des pratiques fondées sur la collaboration : jeu de l'acteur, arts numériques, arts plastiques, performance, etc. Il est le fruit d'un dialogue exploratoire qui s'établit avec une équipe hétérogène (des acteurs, des non-acteurs, des danseuses, des chanteuses, des performeurs, des musiciens, des plasticiennes). Cette manière de travailler est évidemment constitutive de la mise en espace comme pratique interdisciplinaire et hétéromorphique. 
CONCLUSION 
Cette recherche création s'est construite dans une dynamique qui puisse donner idée d'une pensée en mouvement qui appréhende des potentialités, crée des opportunités et des conjonctions inédites afin d'apprivoiser des flux et des courants pour en faire des forces agissantes. C'est dans cet esprit que j'ai voulu faire le repérage d'un certain nombre de fliations esthétiques. J'ai pu y débusquer des notions qui me sont utiles pour penser autrement l'espace du théâtre et pour rendre compte de la complexité du monde qui nous entoure. Ainsi, bien au-delà de la perspective historique que cette traversée suggère, j'aurai pu montrer que plusieurs des explorations menées par les avant-gardes historiques se sont disséminées dans la pratique théâtrale contemporaine pour la déplacer de ses ancrages traditionnels. En outre, ces différents mouvements suggèrent autant d'attitudes qui impulsent de nouvelles modalités d'action qui elles-mêmes élargissent les possibilités d'échanges entre les disciplines pour réinventer les paramètres d'une pratique et renouveler son rapport au réel.

Ce mémoire a aussi été l'occasion d'échafauder une articulation théorique qui prétend démontrer que le concept de mise en espace contribue à la transgression des cloisonnements disciplinaires et ouvre à une variété de pratiques et de formes au théâtre. En fait, je considère que la conceptualisation de l'espace comme opérateur intermédial de rencontres interdisciplinaires et hétéromorphiques stimule les modes de fabrication de l'événement, ses dimensions processuelle, expérientielle et interrelationnelle. De plus, le théâtre du dispositif permet de concevoir une situation, une manière de susciter un être- 
ensemble et d'ébranler une distance esthétique de manière plus ou moins provocante, afin de produire différentes propositions sensorielles à l'endroit du spectateur qui se trouve alors dans une situation de coprésence. Cette situation est construite dans le dessein de convoquer de manière ludique la relation mutuelle entre l'individu et le collectif, ravivant ainsi son expérience du monde.

En outre, j'ai élaboré une approche d'inspiration phénoménologique au théâtre qui me permet de conduire des explorations qui visent à produire un être au monde dans un rapport dialogique et hétéromorphique entre individus appartenant au même socius. Cette méthode de travail me semble opérationnelle autant pour concevoir des dispositifs contextuels et interrelationnels que pour diriger des acteurs (et des non-acteurs) dans leur prise en charge de la parole afin de dépsychologiser le jeu. Elle favorise aussi le développement d'une concentration ouverte sur le monde qui suppose une conscience phénoménologique de la corporéité pour engager des échanges sensibles avec l'Autre. Elle permet de déjouer le sens univoque, et d'instaurer la pluralité du sens, voire des sens, sollicitant alors l'acteur et le spectateur dans son être au monde.

Je pense aussi avoir démontré comment il me semblait nécessaire de dérouter nos habitudes de perception, d'installer des ambigütés dans les significations et de délocaliser les structures dans lesquelles nous sommes habitués d'évoluer, conditionnés par les pensées génériques et la Société du spectacle. En ce sens, j'estime qu'il est nécessaire de mettre en 
échec la représentation en transgressant l'espace scénique traditionnel ${ }^{113}$. Une manière de constituer une stratégie symbolique pour m'arracher au décor (représentationcontemplation-anesthesis) et d'expérimenter de nouveaux descorps (présentation-actionaisthesis). D'être dans l'effectuation, in actu, sans souci de représentation. Je cherche un peu à braver la réalité en contextualisant notre rapport au réel dans un processus qui joue avec les effets de présence, de réel et de fiction. Je pense que l'on peut ainsi développer une manière ludique de comprendre, d'appréhender l'espace et le temps dans lequel nous vivons et admettre que les frontières puissent être instables, mouvantes et poreuses.

Le théâtre rend possible l'expérience d'un incessant et complexe va-et-vient entre la théorie et la pratique. $11 \mathrm{~m}$ 'apparait comme un médium qui se dévoile comme vaste laboratoire de recherche et de création qui favorise à la fois des saisies inouïes et des frustrations qui ont pour effet de me relancer pour les prochaines explorations. Une manière d'être en mouvement, chargée du désir de porter une attention soutenue au travail des artistes, des poètes, des écrivains et des philosophes. En ce sens, plusieurs constellations m'habitent; elles se dessinent, avec leurs échos, leurs résonances, leurs points contrastés voire contradictoires avec lesquelles je cherche à dialoguer. Et puis j'oserais dire aussi qu'une certaine visée chamanique m'anime.

Chamanisme est un mot magique. Plus qu'une image, plus qu'un simple nom renvoyant à une forme de magie, il est un véritable talisman : il porte en lui son propre principe. Il suffit de prononcer ce mot pour éveiller nos sens et notre conscience plus ou moins endormis aux rêves les plus insensés qu'il provoque

${ }^{123}$ Sans pour autant rejeter les dispositifs qui proposent des rapports de frontalité. 
ou qu'il suscite. Le mot chamane « incame » ce qu'il nomme : il fait ce qu'il dit. Il a son efficience propre: un pouvoir, une puissance, une « efficacité symbolique ». Plus qu'une forme ou une figure, il est une « force formatrice » : il fabrique, façonne, agit, produit ses propres effets sur la conscience, crée ou donne vie à la chose même qu'il désigne. Bref, il est poïétique de part en part: sa seule énonciation fait naître ou apparaître devant soi le monde quasi invraisemblable dont il parle ${ }^{114}$.

Le théâtre que je veux développer émane de la sensation d'être habitée par l'énergie du faire, du dire et du désir. Du besoin du geste dans un présent ouvert. Dans un appétit de soi formulé par l'interrogation de l'Autre, avec une soif de recherche et d'expérimentations. Faire, dire, inventer, jouer avec toutes sortes de questions où il est toujours question de questions. Pour apprendre. Une façon de témoigner de mon rapport à la réalité, nécessairement multiple et des perceptions de mon corps atomique. Car le corps n'est pas qu'un objet (anatomique) parmi les autres dans l'indifférence des choses, il est le pivot qui rend le monde possible. La trame sensorielle d'une chair toujours en résonance. La condition sine qua none.

Considérant que la pensée sur le corps est au cour de la pensée sur le monde et dans la perspective qui m'anime, je pense qu'il est urgent de réintégrer la perversité polymorphe de l'humain, (inscrite dans la diversité et la singularité des corps) pour répondre du réel et présenter la vie dans tous ses états. C'est pourquoi $11 \mathrm{~m}$ 'a semblé essentiel de convoquer des

\footnotetext{
114 Texte de présentation de Pierre Ouellet "La parole émissaire » in OUELLET, P. ASSELN, G. (dir.) Puissances du verbe : Écriture et chamanisme, Montréal, VLB, coll. «Le soi et l'autre », 2007, p. 7.
} 
sujets incarnés, désireux de vivre des expériences intersubjectives qui les déplacent joyeusement de leurs repères habiuels pour participer au déambulatoire Filles de guerres lasses. Cette aventure de création a rassemblé une communauté d'hommes et de femmes composée d'artistes de tous âges et de toutes catégories qui a, en quelque sorte, incarné l'hétéromorphisme de ma pratique. Cette pluralité s'est présentée comme une communauté éphémère, fictive et vivante à la fois, toute occupée à tisser avec le réel, qu'à fabriquer les différentes situations contextuelles spécifiquement conçues pour accueillir les spectateurs afin qu'ils participent et achèvent à leur façon les différentes propositions esthétiques suggérées par les lieux eux-mêmes, mais aussi par les textes de Dominick ParenteauLebeuf.

Malgré l'ère de désenchantement postmoderne dans lequel nous nous trouvons, il m'apparaît vital de m'engager à proposer des occasions pour construire et donner du sens au monde dans lequel nous vivons. J'estime que mon approche de mise en espace au théâtre me permet de déployer des dispositifs qui supportent des questionnements philosophiques aux dimensions politiques et sociocritiques. Il m'importe d'ouvrir des perspectives qui me permettent de me projeter au cœur du monde et des miens pour contribuer à la réflexion, mue par une pulsion participative ou " agorétique " ${ }^{115}$ affirmant par là-même, et au-delà des thèmes de création choisis, une attitude socialement engagée.

\footnotetext{
115 bid., p. 37.
} 
En terminant, j'estime que ce mémoire ainsi que la création de l'événement déambulatoire Filles de guerres lasses témoignent véritablement d'un processus de théorisation en action de la recherche en pratique artistique ${ }^{116}$. Je pense avoir su démontrer en quoi consiste la dynamique d'ensemble de ma pratique (particulièrement en ce qui a trait à la relation de circulation qui s'établit entre mes visées conceptuelles, la projection de l'œuvre à faire et la réalisation, voire l'expérience de la création). Faire un retour réflexif sur la mise en espace d'un projet de création de l'envergure de Filles de guerres lasses ne peut être que bien partiel dans le cadre d'une conclusion. J'aimerais néanmoins revenir succinctement sur un aspect essentiel de ma recherche pratique, c'est-à-dire la prise en considération du spectateur dès la conception du projet de mise en espace et son actualisation dans le mode déambulatoire ${ }^{117}$.

Cette création m'aura d'abord permis de constater que le concept de mise en espace est particulièrement opérationnel pour créer de l'être ensemble. La mise en espace entraîne une situation de coprésence intensifiée par des propositions qui sont in situées et qui ont des impacts majeurs sur la réception du spectateur. Non seulement il doit participer physiquement à la situation, (et cela se présente autant par la disposition de son corps parmi des corps que dans le découpage d'espaces et de temps singuliers qui sont autant de manières d'être ensemble ou séparés, en face ou au milieu de, dedans ou dehors, proches ou

\footnotetext{
${ }^{116}$ Pierre Gosselin, «La recherche en pratique artistique. Spécificité et paramètre pour le développement de méthodologies ", in La recherche création Pour une compréhension de la recherche en pratique artistique, sous la dir. de Pierre Gosselin et Éric Le Coguiec, Québec, Presses de l'Université du Québec, 2006, p. 21-31.

${ }^{117}$ Précisons que je ne souhaite pas nécessairement développer une expertise particulière dans le mode déambulatoire. Ce projet exploratoire visait essentiellement à dynamiser les hypothèses de recherche développées dans ce mémoire.
} 
distants, dans l'image ou hors champ, à la vue ou dans la pénombre); il doit aussi élaborer le sens à mesure que ses sens et son imagination sont sollicités par les configurations esthétiques données; il en arrive alors à percevoir l'environnement qui l'entoure (l'architecture, le paysage, les sites quotidiens mais aussi « la matrice infiniment fertile de l'apparaitre imprévisible ${ }^{118}$ ) comme un univers de signes qui lui font signe pour enrichir la proposition dramaturgique. C'est ainsi que le spectateur prend conscience de son processus de subjectivation et admet que la nature processuelle de l'œuvre, son caractère fluant et mouvant, toujours dans l'en cours de son élaboration, soit un pivot essentiel de l'événement. De toute évidence, la mise en espace ravive l'expérience sensible du monde et nous révèle son hétérogénéité constitutive. Elle permet d'accueillir l'altérité et de se sentir au cour de la conscience d'un monde au langage polyphonique. Le mode déambulatoire aura aussi permis de faire ressentir les espaces entre comme des moments de flottement, voire de frottement, en tension vers quelque chose qui est à la fois en soi et hors de soi, une solitude dans la multitude, «nous ne sommes pas seulement des êtres-là, dans la proximité du monde qui nous entoure en nous apparaissant, mais des êtres-avec qui ne sont au monde qu'ensemble ${ }^{119}{ }^{\prime}$. Je considère que le concept de mise en espace permet d'ouvrir un nouveau champ dramaturgique qui recèle une puissance à la fois créatrice, génératrice et régénératrice pour le théâtre contemporain. Il y a là, sans aucun doute, matière à poursuivre la recherche et la création. C'est à la fois une promesse et un engagement.

\footnotetext{
${ }^{118}$ Expression tirée du livre de Pierre Ouellet, Quel Autre? L'Altérité en question, op.cit. p.21.

${ }^{119}$ Ibid., p. 32.
} 


\section{BIBLIOGRAPHIE}

AGAMBEN Giorgio, Enfance et histoire, Paris, Petite Bibliothèque Payot, 2002.

ARDENNE Paul, Un art contextuel, Paris, Flammarion, coll. « Champs », 2004.

ARTAUD Antonin, Euvres, Paris, Gallimard, coll. «Quarto », 2004.

BACHELARD Gaston, L'Eau et les Rêves, Paris, José Corti, 1942.

BARBA Eugenio, Le canoë de papier. Traité d'Anthropologie Théatrale, Saussan, L'Entretemps, coll. «Les Voies de l'acteur », 2004.

BARBA Eugenio, La terre de cendres et diamants. Mon apprentissage en Pologne, suivi de 26 lettres de Jerzy Grotowski à Eugenio Barba, Saussan, L'Entretemps, coll. "Les Voies de l'acteur », 2000.

BARTHES Roland, Le grain de la voix. Entretiens 1962-1980, Paris, Éditions du Seuil, coll. « Points/essais $», 1981$.

BARTHES Roland, Ecrits sur le théâtre, Paris, Éditions du Seuil, coll. " Points/essais, $\mathrm{n}^{\circ} 492$ », 2002.

BRUNEAU Monik et VLLENEUVE André (dir.), Traiter de recherche création en art : Entre la quête d'un territoire et la singularité des parcours, Québec, Presses de l'Université du Québec, 2007.

BUCI-GLUCKSMANN, Christine, Esthétique de l'éphémère, Paris, Galilée, 2003.

CAUQUELIN Anne, Le site et le paysage, Paris, PUF, coll. « Quadrige », 2002.

CHAMBERLAND Roger et MARTEL Richard (dir.), Oralités - Polyphonix 16 « La pensée se fait dans la bouche », Québec, Les Éditions Intervention \& CRELIQ, 1992.

DEBORD Guy, La Société du spectacle, Paris, Gallimard, coll. «Folio/essais », 1992.

DEBORD Guy, Les Lèvres nues, n6, Bruxelles, 1955.

DELEUZE Gilles, Francis Bacon. Logique de la sensation, Paris, Éditions du Seuil, coll. «L'ordre philosophique $», 2002$.

DERRIDA Jacques, L'écriture et la différence, Paris, Éditions du Seuil, coll. «Tel quel », 1967. 
DIDI-HUBERMAN Georges, Ce que nous voyons, ce qui nous regarde, Paris, Edition Minuit, coll. «Critique », 1992.

FAGOT Sylvain et UZEL Jean-Philippe (dir.), Énonciation artistique et socialité, Paris, L'Harmattan, coll. «Logiques sociales », 2006.

FOUCAULT Michel, Dits et écrits II 1976-1988, « Des espaces autres », Paris, Gallimard, coll. « Quarto », 2001, p. 1571-1581.

GOLDBERG Roselee, La Performance, du futurisme à nos jours, Paris, Thames \& Hudson, 2006.

GOSSELIN Pierre et LE COGUIEC Éric, (dir.), La recherche création : Pour une compréhension de la recherche en pratique artistique, Québec, Presses de l'Université đu Québec, 2006.

GROTOWSKI Jerzy, Vers un théatre pawre, Lausanne, L'Age d'Homme, 1971.

HAMON-SIRÉJOLS Christine et SURGERS Anne (dir.), Théatre: espace sonore, espace visuel, Lyon, Presses Universitaires de Lyon, 2003.

INTERNATIONALE SITUATIONNISTE, Paris, Librairie Arthème Fayard, 1997.

LAURIER Diane et GOSSELIN Pierre (dir.), Tactiques insolites: Vers une méthodologie de recherche en pratique artistique, Montréal, Guérin, 2004.

LEHMANN, Hans-Thies, Le Théâtre postdramatique, Paris, L'Arche, 2002.

LUSSAC Olivier, Happening \& Fluxus polyexpressivité et pratique concrète des arts, Paris, L'Harmattan, coll. «Arts \& Sciences de l'ar 1 », 2004.

LYOTARD Jean-François, Des dispositifs pulsionnels, Paris, Christian Bourgois, coll. «10/18», 1980.

MERLEAU-PONTY Maurice, Phénoménologie de la perception, Paris, Gallimard, coll. «Tel », 1945.

NOVARINA Valère, Pour Louis de Funès, précédé de Lettre aux acteurs, Arles, Actes Sud, 1986.

OUELLET Pierre, HAREL, Simon (dir.), Quel Autre? L'altérité en question, Montréal, VLB éditeur \& Le soi et l'autre, 2007.

OUELLET Pierre et ASSELIN Guillaume (dir.), Puissances du verbe; Écriture et chamanisme, Montréal, VLB éditeur \& Le soi et l'autre, 2007.

PARENTEAU-LEBEUF, Dominick, Filles de guerres lasses, Morlanwelz (Belgique), Lansman, coll. « Nocturnes Théâtre », 2005.

PAVIS Patrice, La mise en scène contemporaine. Origines, tendances, perspectives, Paris, Armand Colin, 2007. 
PICARD, Timothée, L'art total. Grandeur et misère d'une utopie (autour de Wagner), Rennes, Presses Universitaires de Rennes, coll. «Aesthetica», 2006.

PONTBRIAND Chantal, Fragments critiques (1978-1998), Nîmes, Éd. Jaqueline Chambron, coll. « Critiques d'Art $», 1998$.

RANCIÈRE Jacques, Le spectateur émancipé, Paris, La Fabrique, 2008.

RANCIÈRE Jacques, Le Partage du sensible. Esthétique et politique, Paris, La Fabrique, 2000.

RÉGY Claude, Espaces perdus, Besançon, Les solitaires intempestifs, 1998.

RYNGAERT Jean-Pierre (dir.), Nowveaux territoires du dialogue, Arles, Actes SudPapiers/CNSAD, coll. « Apprendre », 2005.

RUSSOLO Luigi, L'Art des bruits, manifeste futuriste 1913, Paris, Éditions Allia, 2006.

TACKELS Bruno, François Tanguy et le Théâtre du Radeau, Besançon, Les solitaires intempestifs, coll. « Les écrivains de plateau II », 2005.

SAINT GIRONS Baldine, L'acte esthétique, Paris, Klincksieck, coll. «50 questions », 2008.

THOMAS Florence, (coor.) L'assemblée théâtrale, Paris, Éditions de L'Amandier, 2002.

TREMBLAY Larry, Le crâne des théatres Essais sur les corps de l'acteur, Montréal, Leméac, 1993.

VANDER GUCHT Daniel, Art et politique. Pour une redéfinition de l'art engagé, Bruxelles, Éditions Labor, coll. «Quartier Libre», 2004.

\section{ARTICLES ET PERIODIQUES}

BAILLET Florence, «L'hétérogénéité 》 in Nouveaux territoires du dialogue, sous la dir. de Jean* Pierre Ryngaert, Arles, Actes Sud-Papiers/CNSAD, coll. « Apprendre », 2005, p. 26-30.

BAUCHARD Frank, «Esthétiques des mutations scéniques 》, in Etudes théâtrales, Arts de la scène, scène des arts, n² \& 29, 2003-2004, vol. II «Limites, horizon, découvertes : mille plateaux ", Louvain-la-Neuve, (Belgique), p. 131-138.

BOUCRIS Lac, «S'installer ou divaguer? Déambuler! in Études théâtrales, Arts de la scène, scène des arts, n’30, 2004, vol. II, «Formes hybrides : vers de nouvelles identités », Louvain-laNeuve (Belgique), p. 73-83. 
CHAMBERLAND Roger, "Oralité protéiforme », in Oralités - Polyphonix 16 «La pensée se fait dans la bouche ", CHAMBERLAND Roger et MARTEL Richard (dir.), Québec, Les Éditions Intervention \& CRELIQ, 1992, p. 9-12.

FÉRAL Josette, «Entre performance et théâtralité : le théâtre performatif 》, in Théatre/Public « L'avant-garde américaine et l'Europe, 1. Performance $», n^{\circ} 190,2008$, p. 28-35.

FÉRAL Josette, «Un corps dans l'espace : perception et projection », in Théâtre : espace sonore, espace visuel, Lyon, Presses Universitaires de Lyon, 2003, p. 127-143.

GUATTARI Félix, «L'oralité machinique et l'écologie du virtuel », in Oralités - Polyphonix 16 « La pensée se fait dans la bouche », CHAMBERLAND Roger et MARTEL Richard (dir.), Québec, Les Éditions Intervention \& CRELIQ, 1992, p. 25-32.

GUAY Hervé, «Vers un dialogisme hétéromorphique », in Tangence, n 88, automne 2008, p. 6376.

HÉBERT Chantale (dir), L'annuaire théâtral, « Regards croisés : théâtre et interdisciplinarité 》, n'26, automne 1999, CRELIQ/SQET, Ottawa.

LESAGE Marie-Christine, "L'interartistique : une dynamique de la complexité » in Registres/13, « Thêâtre et interdisciplinarité », printemps 2008, Presses Sorbonne Nouvelle, Paris, p. 11-26.

LUPIEN Jocelyne, «Sensation, perception, représentation : l'art comme expérience sensible », in Énonciation artistique et socialité, (dir. Sylvain Fagot et Jean-Philippe Uzel), Paris, L'Harmattan, coll. « Logiques sociales », 2006, p. 47-56.

RYKNER Amaud, « Du dispositif et de son usage au théâtre », Tangence, n 88, automne 2008, p. 91-103.

SARRAZAC Jean-Pierre, "Le partage des voix », in Nouveaux territoires du dialogue, sous la dir. de Jean-Pierre Ryngaert, Arles, Actes Sud-Papiers/CNSAD, coll. «Apprendre », 2005, p. 11-16.

TRUONG Nicolas, «Itinéraire d'un penseur sans frontières », in Le Monde//Hors Série, coll. " Une vie, une œuvre. Edgard Morin, Le philosophe indiscipliné », date n.d., Paris, p. 7-20.

ZUMTHOR Paul, «Sonorité, oralité, vocalité », in Oralités - Polyphonix 16 "La pensée se fait dans la bouche ", CHAMBERLAND Roger et MARTEL Richard (dir.), Québec, Les Éditions Intervention \& CRELIQ, 1992, p. 17-24. 